DOE/NASA/20320-59

NASA TM-83680

NASA-TM- 83680

19840021278

\title{
Effect of Vortex Generators on the Power Conversion Performance and Structural Dynamic Loads of the Mod-2 Wind Turbine
}

Timothy L. Sullivan

National Aeronautics and Space Administration Lewis Research Center

June 1984

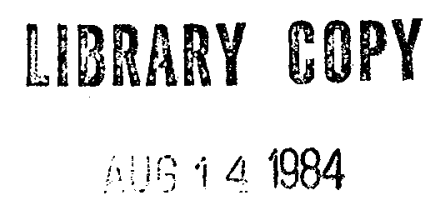

LANGLEY RESEARCH CENTER LIBRARY, NASA HAMPTON, VIRGINIA

Prepared for

U.S. Department of Energy

Conservation and Renewable Energy

Wind Energy Technology Division 


\title{
DISCLAIMER
}

This report was prepared as an account of work sponsored by an agency of the United States Government. Neither the United States Government nor any agency thereof, nor any of their employees, makes any warranty, express or implied, or assumes any legal liability or responsibility for the accuracy, completeness, or usefulness of any information, apparatus, product, or process disclosed, or represents that its use would not infringe privately owned rights. Reference herein to any specific commercial product, process, or service by trade name, trademark, manufacturer, or otherwise, does not necessarily constitute or imply its endorsement, recommendation, or favoring by the United States Government or any agency thereof. The views and opinions of authors expressed herein do not necessarily state or reflect those of the United States Government or any agency thereof.

\author{
Printed in the United States of America \\ Available from \\ National Technical Information Service \\ U.S. Department of Commerce \\ 5285 Port Royal Road \\ Springfield, VA 22161 \\ NTIS price codes 1 \\ Printed copy: A02 \\ Microfiche copy: A01
}

${ }^{1}$ Codes are used for pricing all publications. The code is determined by the number of pages in the publication. Information pertaining to the pricing codes can be found in the current issues of the following publications, which are generally available in most libraries: Energy Research Abstracts (ERA); Government Reports Announcements and Index (GRA and 1); Scientific and Technical Abstract Reports (STAR); and publication, NTIS-PR-360 available from NTIS at the above address. 


\section{Effect of Vortex Generators on the Power Conversion Performance and Structural Dynamic Loads of the Mod-2 Wind Turbine}

Timothy L. Sullivan

National Aeronautics and Space Administration

Lewis Research Center

Cleveland, Ohio 44135

June 1984

Work performed for

U.S. DEPARTMENT OF ENERGY

Conservation and Renewable Energy

Wind Energy Technology Division

Washington, D.C. 20545

Under Interagency Agreement DE-Al01-76ET20320 


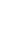




\title{
EFPECT OF VORTEX GENERATORS ON THE POWER CONVERSION PERFORMANCE
}

\section{AND STRUCTURAL DYNAMIC LOADS OF THE MOD-2 WIND TURBINE}

\author{
T. L. Sullivan \\ National Aeronautics and Space Administration \\ Lewis Research Center \\ Cleveland, Ohio 44135
}

\begin{abstract}
SUMIMARY
The Department of Energy wind turbine cluster at Goldendale, Washington, was used to test a method for improving the drive train stability and power conversion performance of the Mod-2 wind turbine. The method consisted of bonding small metal vanes, called "vortex generators" (VG's) onto the rotor blades. The objective of the tests was to measure the effect of adding VG's on power conversion performance and dynamic loads. The test procedure was first to obtain baseline data without VG's on the rotor. Next, two vortex generator configurations were tested. The first had VG's on the fixed portion of the rotor (20 to 70 percent span); the second had VG's added out to the tip of the pitchable portion of the blade ( 70 to 100 percent span).
\end{abstract}

Over $30 \mathrm{hr}$ of test data were processed and analyzed. To evaluate performance, 10 min averages of generator power and wind speed were used. To evaluate cyclic loads, the data were divided into half-hour segments and statistical analysis performed on each segment to obtain cumulative probability distributions. Median and 99 th percentile levels were used in assessing the effect of adding VG's. Blade, drive train, and tower loads were reviewed. Cyclic loads were found to correlate well with the change in wind speed during one rotor revolution. This change is one measure of wind turbulence, and it was used to help reduce data scatter in assessing the effect of VG's on dynamic loads.

Performance test results showed that the addition of vortex generators to the Mod-2 rotor blades resulted in a significant increase in power and annual energy capture. Application of VG's to the fixed portion of the rotor reduced the wind speed at which rated power is reached from about 16 to $13.8 \mathrm{~m} / \mathrm{sec}$ and increased projected annual energy capture by 11 percent. The addition of VG's out to the rotor tip reduced rated wind speed an additional $0.5 \mathrm{~m} / \mathrm{sec}$ and increased projected annual energy capture an additional 9 percent. This increase in performance came at little cost in increased cyclic loads. No significant difference in cyclic loads was found between the two VG configurations tested. A slight increase in blade cyclic loads in below rated power winds was found after the addition of VG's. However, because the addition of VG's also results in a decrease in peak steady loading, the overall effect of adding VG's is probably to increase blade fatigue life.

\section{INTRODUCTION}

The Mod-2 wind turbine cluster (fig. 1 , and refs. 1 and 2 ) near Goldendale, Washington, is presently a major element of the Federal Wind Energy Program administered by the U. S. Department of Energy (DOE). The cluster consists of three large, horizontal-axis wind turbines, each rated at $2.5 \mathrm{MW}$, arranged in a triangular array (fig. 2). The important features of the Mod-2 machines are given in figure 3 . One of the purposes of the cluster is to test methods for improving the operational characteristics and performance of existing and planned wind turbines. Test activity is supported by DOE 
and the Electric Power Research Institute (EPRI). NASA Lewis Research Center has management responsibility for the Mod-2 cluster research program (ref. 3 ).

In a company sponsored effort, the Boeing Engineering Company (BEC) conceived and developed a method for improving wind turbine drive train stability and power conversion performance (ref. 4). This method consisted of mounting small metal vanes or vortex generators (VG's) on the rotor blades. In the past VG's have been used on the wings of aircraft to improve performance, but this is their first application to large, horizontal-axis wind turbine rotors. Vortex generators energize the boundary layer by mixing higher energy air from the free stream with boundary layer air. This increases the angle of attack at which stall occurs. Factors involved in the design of VG's can be found in reference 5 . Initial testing of the vortex generator concept took place on a Mod-2 wind turbine located in Solano County, California. This unit is owned and operated by the Pacific Gas and Electric Company.

Because of the success of the initial testing, a detalled study of the effect of vortex generators on wind turbine control behavior, power conversion performance, and structural dynamic loads was conducted using a single machine of the Goldendale cluster. The test procedure was to collect performance and load data for three Mod-2 rotor configurations. In the first configuration, which provided baseline data, the Mod- 2 was operated without VG's on the rotor. In the second configuration the Mod-2 was operated with VG's on the fixed span of the rotor. In the third, VG's were added to the pitchable tip. Nearly $40 \mathrm{hr}$ of synchronized operational time were accumulated in these three configurations. From this time $33 \mathrm{hr}$ of performance data and $30.5 \mathrm{hr}$ of loads data were analyzed.

The primary objective of this report is to document and evaluate the results of the vortex generator tests conducted at Goldendale. In addition, the report describes in detail the Mod-2 test configurations, including vortex generator dimensions and spacing. The data collection and processing procedures used are described, including a method for reducing data scatter by accounting for small scale turbulence effects.

\section{MOD-2 TEST CONFIGURATION}

The vortex generator tests were conducted during July and August of 1983 using Unit 3 of the Mod-2 cluster at Goldendale, Washington. In this section the Mod-2 rotor and the vortex generator configurations tested are described. Because control system parameters have an important effect on wind turbine performance and loads, the control system configuration in place during these tests is documented here.

\section{Rotor Blades and Vortex Generators}

The Mod-2 rotor is a welded steel structure (fig. 4(a)). The outer 30 percent of each blade can be rotated (pitched) for startup and shutdown and to control power. The aerodynamic features of the blade (airfoil type, thickness, chord, and twist) are shown in
figure $4(\mathrm{~b})$.

The vortex generator (VG's) used for these tests consisted of small tabs fabricated from $0.051 \mathrm{~cm}(0.020$-in.) thick aluminum sheet. They were bonded to the low-pressure side of the rotor blades in pairs as shown in figure 5 . Three sizes were used, depending on the spanwise location of the VG. The VG dimensions and spacing for each configuration are shown in the figure. A photograph of each configuration and of the VG's mounted on the Mod-2 rotor are shown in figure 6. 
Before VG's were applied to the rotor, baseline data were obtained. This is called the no VG configuration. Testing with VG's applied was conducted in two stages. In the first, VG's were applied from station 367 to 1245, the fixed portion of the Mod-2 blade. This is called the 70 percent VG configuration. In the second stage VG's were added from station 1164 to 1796 , the pitchable portion of the blade. This is called the 100 -percent VG configuration.

\section{Control System}

The Mod-2 control system in place during the vortex generator tests was the result of an evolutionary process that began with first operation of the Mod-2 machines at Goldendale in early 1981. Details of the control system history can be found in reference 2. The blade tips are pitched not only to control power, but also to provide drive train damping (hub rate damping). To reduce the effect of blade tip motion on cyclic tower loads, the control system contains a notch filter at the tower natural frequency. Other control system parameters that effect wind turbine loads and performance are the below rated power pitch schedule and the pitch angle limit.

Por the vortex generator tests (this includes the no VG configuration tests) a very narrow, $-9 \mathrm{~dB}$ variable gain tower notch filter was in place. The blade pitch schedule was $+5^{\circ}$ from 0 to $1 \mathrm{MW}$ and $+2^{\circ}$ from $1 \mathrm{MW}$ to rated power ( + indicates the direction towards feather). The pitch angle limit for hub rate damping motion was $+2^{\circ}$.

\section{DATA COLLECTION AND PROCESSING PROCEDURES}

\section{Standard Procedures}

The standard DOE/NASA engineering data system at the Goldendale test site (ref. 6) was used to collect data from the sensors on analog tape. These sensors and their ranges are listed in table I. The details of the data in each of the three data sets are given in table $\Pi$. The analog tapes were shipped to NASA Plum Brook Station where they were digitized at a rate of 250 readings per rotor revolution. These data were compressed by selection of the maximum and minimum value for each rotor revolution. The compressed, digitized data were recorded on tape for subsequent analysis on a Lewis Research Center mainframe computer.

The first step in the analysis was to calculate midpoint or steady $(1 / 2$ (maximum + minimum)) and cyclic ( $1 / 2$ (maximum - minimum)) values for each rotor revolution. From this point one of two paths was followed. For analysis of power conversion performance, 10-min averages of midpoint generator power and wind speed were calculated. For analysis of dynamic effects the DOE/NASA standard statistical analysis (ref. 6) was used. Among other things the standard analysis provides cumulative probability distributions of midpoint and cyclic values. For this study statistics were done on 30 -min segments of wind turbine operation. From these statistics 50 th percentile (median) and 99 th percentile values were used to determine the effect of vortex generators on the dynamic response of the Mod-2 wind turbine.

Performance data were available both in the form of 10 -min averages and cumulative probability distributions for $30 \mathrm{~min}$ of operation. These data were used to determine whether any difference in the results would be obtained using the two 
procedures. In figure 7,10 -min averages can be compared with median values from 30 min of operation. Curve fits of the two data sets are nearly identical. The data in figure 7 are for the no VG configuration. Similar results were obtained for the 70 and 100 percent VG configurations. This comparison shows that the two data processing procedures will produce identical or nearly identical results.

\section{Special Procedures for Loads Analysis}

The dynamic response of a wind turbine is the result of a number of factors including steady wind speed, wind shear, wind turbulence, terrain effects, and control activity. The Mod-2 rotor is teetered, which should minimize blade load response to wind shear. During the vortex generator tests, the wind was predominantly from the west $\left(270^{\circ}\right)$. The averages of half-hour median values of wind direction were $269^{\circ}, 266^{\circ}$, and $263^{\circ}$ for the no VG, 70-percent VG, and 100-percent VG tests, respectively. Therefore, any terrain effects on the test data should be small:

From an initial review of the load data, it was clear that wind turbulence as measured by cyclic wind speed was having a strong effect on wind turbine response. Table III presents data measured during two half-hour segments that were separated by a 20-min machine shutdown. During the shutdown, the median steady wind speed remained nearly constant, but a significant change in the steady wind standard deviation and in the cyclic wind speed did occur. Cyclic wind speed $V_{c}$ is one-half the change in wind speed at hub elevation during one rotor revolution. The standard deviation $\sigma$ is generally used as the measurement of turbulence in the wind. However, in other investigations (Zimmerman, et al., ref. 7, for example) little correlation has been found between $\sigma$ and wind turbine dynamic response. This is probably because o represents a phenomenon taking place over a period considerably longer than one rotor revolution. On the other hand, because cyclic wind speed represents a change in wind speed over one rotor revolution, a relationship between cyclic wind and wind turbine response should be present. Because it measures a change over a relatively short period of time ( $3.4 \mathrm{sec}$ for the Mod-2), $V_{c}$ is a small number and, therefore, potentially subject to significant error from noise in the data system. However, the data available for the vortex generator study were exceptionally free from noise. The noise on the cyclic wind speed signal was estimated to be in the range of 0.05 to $0.10 \mathrm{~m} / \mathrm{sec}$. No attempt was made to correct for this error.

The relationship between steady and cyclic wind speed during the vortex generator tests is shown in figure 8 . The general trend of the data shows that cycllc wind speed increases with steady wind speed but that the data scatter is significant. Linear curve fits for the data sets show that for like probabilities no large difference existed between them. The data in figure 8 were used to help in the selection of three narrow, steady-wind bins, where the variation in cyclic wind speed was large without regard to VG configuration. The wind bins selected were $0.2 \mathrm{~m} / \mathrm{sec}$ wide and were centered about 9.65 , 12.15 , and $14.75 \mathrm{~m} / \mathrm{sec}$. Cyclic blade load data from these three bins were used to determine if there was a correlation between cyclic wind and cyclic loads.

Cyclic blade loads are plotted against the square root of cyclic wind speed $\left(\mathrm{V}_{\mathrm{c}}\right)^{0.5}$ using 50th and 99 th percentile data (fig. 9). The parameter $\left(\mathrm{V}_{\mathrm{c}}\right)^{0.5}$ is used because the data in table III show the loads to be about in proportion to this parameter. The loads show excellent correlation with $\left(V_{c}\right)^{0.5}$ : all the data fall within the same relatively narrow band. The effect of an increase in steady wind speed is only to move the data
upward in this band. 
To isolate the effect of configuration changes, such as adding vortex generators in the blades, it is helpful to first account for other changes. From the foregoing it is clear that the most important of these is changes in turbulence. To account for variations in wind turbulence, the cyclic loads data (to be presented in later sections) were plotted versus a wind speed/turbulence parameter $\mathrm{V}_{\mathrm{WT}}$, which is the product of the steady wind speed and the square root of the cyclic wind speed. In figure 10(a) blade flatwise cyclic moment is plotted against steady wind speed. In figure $10(\mathrm{~b})$ the data are plotted against $\mathrm{V}_{\text {WT }}$. Data scatter has been reduced by a factor of eight, as measured by summing the squares of the residuals. The data in figure 10 are for the no VG configuration. This approach also resulted in reduced data scatter for both VG configurations.

\section{POWER CONVERSION PERFORMANCE}

The primary purpose of the vortex generator tests was to determine their effect on power conversion performance. Measured data for the three configurations (no VG's, 70 percent VG's, 100 percent VG's) are presented in figure 11. The data points represent $10-\mathrm{min}$ averages of generator power and wind speed at $59.4-\mathrm{m}(195-\mathrm{ft})$ elevation from the Bonneville Power Authority (BPA) meteorological tower. They have been corrected to site standard conditions (air density of $1.127 \mathrm{~kg} / \mathrm{m}^{3}$ ) based on hourly measurements of temperature and barometric pressure from the Battelle Pacific Northwest Laboratory (PNL) meteorological tower. The maximum size of this correction was about 5 percent. In every case corrected power was greater than measured power.

The performance benefit of adding VG's to the Mod-2 blades is clearly shown in figure 12. Here second-degree polynominal least-squares best-fit curves of the three data sets are compared. One basis of comparison is the wind speed at which the wind turbine achieves peak power. With no VG's this value exceeded $16 \mathrm{~m} / \mathrm{sec}$. The presence of VG's on 70 percent of span reduced this value to about $13.8 \mathrm{~m} / \mathrm{sec}$, and 100 percent VG's reduced it to about $13.3 \mathrm{~m} / \mathrm{sec}$. Comparing test data curve fits shows that the primary benefit of VG's occurs at higher wind speeds. This is expected because at low wind speeds only a small portion of the blade without VG's would be stalled. Therefore, adding VG's has little effect. At higher wind speeds a significant portion of the blade can be stalled. Adding VG's delays stall and strongly influences power generating capability.

The maximum average power achieved during these tests was about $2450 \mathrm{~kW}$ rather than rated power $(2500 \mathrm{~kW})$. Maximum average power is a function of both power setpoint and any pitch angle limit setting. It appears that a slightly higher power setpoint is required to produce an average peak power equal to rated power.

Another performance figure of merit is annual energy capture. The increase in annual energy capture obtained by installing vortex generators on the Mod- 2 blades was calculated (table IV) using the data curve fits of power versus wind speed shown in figure 12 and a Weibull wind speed distribution for an annual average wind speed of $6.4 \mathrm{~m} / \mathrm{sec}$ ( 14 $\mathrm{mph})$ at $10 \mathrm{~m}(30 \mathrm{ft})$ above ground level. The 70 -percent VG configuration resulted in a projected increase in annual energy of 11 percent, and the 100 percent VG configuration resulted in a 20 percent increase.

The effect of vortex generators on power quality as indicated by cyclic power is presented in figure 13 for below rated power data. Linear curve fits of the data with and without VG's show a very slight increase in cyclic power with VG's at lower values of steady power. When rated power is reached, any difference is no longer evident. From this it is concluded that the addition of VG's to the Mod-2 rotor blades has had a negligible effect on power quality. 


\section{DYNAMIC LOADS}

The previous section has shown the benefit to performance of adding vortex generators to the Mod-2 rotor blades. This section examines any cost in increased dynamic loads that may accompany the performance benefit. The assessment is based on statistical analysis of half-hour segments of data. Blade, drive train (quill shaft), and tower cyclic loads are reviewed. To aid in the assessment of the effect of vortex generators, second-degree polynominal curve fits of the data were generated. Individual curve fits of the 70 percent and 100 percent VG data showed little difference, considering the distribution and scatter of the data. Therefore, a single curve fit was generated for the 70 and 100 percent VG data.

\section{Rotor Blades}

Cyclic bending moment data were obtained at blade stations 370 and 1164 . Flatwise and chordwise measurements were made on both blades. Because blade-to-blade measurements were reasonably close, giving no reason to favor data from one blade over the other, the results presented here are the average from the two blades.

Figure 14 presents cyclic flatwise blade load data at stations 370 and 1164 . Median and 99 th percentile data are shown. The data from both stations show similar trends. At lower values of $V_{W T}$ the rotors with VG's exhibit slightly higher loads. However, as the rotor with VG's approached rated power this difference disappeared. The reason for this is that the rotors with VG's have reached rated power and the blade tips have started to pitch towards feather. Once the blade tips start to pitch back, the rate of increase in cyclic load with increasing $\mathrm{V}_{\mathrm{WT}}$ is significantly reduced. Without VG's the rotor has not yet reached rated power, and the cyclic loads continue to increase at about the same rate. Figure 14 also shows little difference in the maximum data values with and without VG's.

Cyclic chordwise loads (fig. 15) are dominated by gravity, and the bending moments are given in $\mathrm{g}$ 's. At station $370,1 \mathrm{~g}=3.3 \times 10^{6} \mathrm{~N}-\mathrm{m}\left(2.40 \times 10^{6} \mathrm{lb}-\mathrm{ft}\right)$, and, at station 1164 , $1 \mathrm{~g}=0.320 \times 10^{6} \mathrm{~N}-\mathrm{m}\left(0.235 \times 10^{6} \mathrm{lb}-\mathrm{ft}\right)$. Some of the same trends seen in the flatwise data are present here. However, there is very little difference in the median data at lower values of $\mathrm{V}_{\mathrm{WT}}$. Note that the increase in cyclic moment over gravity can be significant. At station 1164 the 99 th percentile values exceeds 1.2 for values of $V_{W T}>12(\mathrm{~m} / \mathrm{sec})^{3 / 2}$.

The similar trends observed in both the flatwise and chordwise data suggest the possibility of coupling between the two. The proportionality of the two is shown in figure 16. This indicates that at least a portion of the increase in chordwise load over gravity is caused by a coupling to flatwise motion induced from twist or control system activity. This kind of coupling has also been noted in the 100-kW Mod-0 and 200-kW Mod-0A wind turbines (ref. 8).

Investigation of steady blade loads was not included in this study primarily because zero shifts from one data set to the next made correct interpretation of these data difficult. However, a qualitative indication of steady blade loads can be obtained from the power curves of figure 12. Steady blade loads increase until rated power is reached. At this point the blade tips begin to pitch back, and the steady component of load begins
to decrease. Because this point is to decrease. Because this point is reached at a lower wind speed for the rotor with VG's, has been achieved are identified on figure 14 with solid symbols. 
In summary, the addition of vortex generators to the Mod-2 rotor has not had a significant effect on cyclic blade loads. High load levels, where most of the fatigue damage is done, are about the same with and without VG's. At wind speeds below rated a small increase in cyclic loading on the rotors with VG's occurrs. When the effect of VG's on steady loads is considered, it is probable that the overall effect is to improve blade fatigue life.

\section{Drive Train}

Cyclic quill shaft torque data are presented in figure 17. The data show a significant increase in cyclic torque with VG's on the rotor. However, it should be remembered that for a given wind speed, the rotor with VG's is producing significantly more power. A plot of cyclic values against steady values (fig. 18) gives a different perspective to the data. Up to rated torque, cyclic torque increases in proportion to steady torque. The addition of VG's makes little difference to this relationship. Any performance enhancing measure, whether it be adding VG's, using a more optimum pitch setting, or some other measure, will produce similar results.

\section{Tower}

The Mod-2 tower is instrumented at station 600 with bending moment sensors on two perpendicular axes. The data from each sensor were processed separately. A resultant bending moment was calculated assuming the load maxima and minima from the two sensors were always in phase. Median and 99 th percentile data from one sensor were matched with like probabilities from the other sensor.

Review of a short length of strip chart data revealed that the actual median phase angle was about $40^{\circ}$; it ranged between $0^{\circ}$ and $70^{\circ}$. The strip charts also showed that high load cycles from one axis did not always correspond to high load cycles on the other axis. Therefore, the calculated resultant moments are "worst case" values and, if used for design, would result in a conservative design.

The effect of adding vortex generators to the Mod-2 rotor on resultant tower cyclic loads is presented in figure 19. For lower values of $V_{W T}$ there is little difference in resultant moment with and without VG's. At higher values of $V_{W T}$ the application of VG's appears to have had a beneficial effect. At the 99 th percentile level the maximum cyclic loads occurred when there were no VG's on the rotor. This reduction in cyclic loading with the addition of VG's to the rotor may be a result of a reduction in the need for hub rate damping blade tip activity with VG's on the blade.

In addition to the apparent reduction in cyclic tower loading with the addition of VG's to the Mod-2 rotor, peak steady loading should be reduced because peak thrust is reduced for the reason discussed earlier. Thus, the addition of VG's has had a doubly beneficial effect on the Mod-2 tower loading. Tower fatigue life should be improved.

\section{CONCLUSIONS}

Performance and structural load data from the Mod-2 vortex generator tests have been processed and analyzed. Based on this analysis the following conclusions are made:

1. Applying vortex generators to the Mod-2 rotor has resulted in a significant improvement in power conversion performance. Application of VG's from 20 to 70 
percent of span has reduced the wind speed required to produce rated power by about 2.2 $\mathrm{m} / \mathrm{sec}$ and increased projected annual energy capture by about 11 percent. The addition of VG's to the rotor blade tips further reduced rated wind speed by $0.5 \mathrm{~m} / \mathrm{sec}$ and increased projected annual energy capture by an additional 9 percent.

2. The improved energy conversion performance brought about by adding VG's to the Mod-2 rotor has come with little or no cost in increased dynamic loads. In below-rated conditions there has been a slight increase in cyclic blade loads. No significant difference was found between the 70 and 100 percent VG configurations. When the beneficial effect of VG's on peak steady loads is considered, it is likely that their addition to the Mod-2 rotor will improve both blade and tower fatigue life.

3. The change in hub level wind speed measured during a rotor revolution (cyclic wind speed) correlated well with cyclic blade loads. This parameter appears to be a useful indicator of small-scale wind turbulence. Accounting for turbulence induced effects using this parameter resulted in reduced data scatter and made it easier to identify the effect of configuration changes on dynamic loads.

Because of its importance to wind turbine dynamic response, it is recommended that cyclic wind speed or a simllar parameter be measured when evaluating wind turbulence at a particular site.

\section{REFERENCES}

1. Mod-2 Wind Turbine System Concept and Preliminary Design Report, Vol. II, Detalled Report. DOE/NASA 0002-80/2, NASA CR-159609, 1979.

2. Mod-2 Wind Turbine System Development, Vol. II, Detailed Report. DOE/NASA 0002-2, NASA CR-168007, 1982.

3. Gordon, L. H.: Mod-2 Wind Turbine System Cluster Research Test Program, Vol. I,. DOB/NASA/20305-8, NASA TM-82906, 1982.

4. Miller, G. E.: Comparative Performance Tests on the Mod-2, 2.5 MW Wind Turbine With and Without Vortex Generators. Paper presented at Horizontal-Axis Wind Turbine Technology Workshop, Cleveland, Oh., May 8-10, 1984.

5. Pearcey, H. H.: Shock-Induced Separation and Its Prevention by Design and Boundary Layer Control. Boundary Layer and Flow Control, Vol. II, G. V. Lachmann, ed., Pergamon Press, 1961, pp 1166-1344.

6. Neustadter, H. E.; and Spera, D. A.: Applications of the DOE/NASA Wind Turbine Engineering Information System. Wind Turbine Dynamics. DOE CONF-810226, NASA CP-2185, 1981, pp. 113-120.

7. Zimmerman, D. K; Shipley, S. A. and Miller, R. D.: Comparison of Measured and Calculated Dynamic Loads for the Mod-2, 2.5 MW Wind Turbine System. Paper presented at Horizontal-Axis Wind Turbine Technology Workshop, Cleveland, Oh., May 8-10, 1984.

8. Spera, D. A.; Janetzke, D. C.; and Richards, T. R.: Dynamic Blade Loading in the ERDA/NASA $100-\mathrm{kW}$ and $200-\mathrm{kW}$ Wind Turbines. ERDA/NASA/1004-77/2, NASA TM-73711, 1977. 
TABLE I. - SENSOR CHARACTERISTICS

\begin{tabular}{|c|c|c|}
\hline Type of sensor & Description & Range \\
\hline Load & 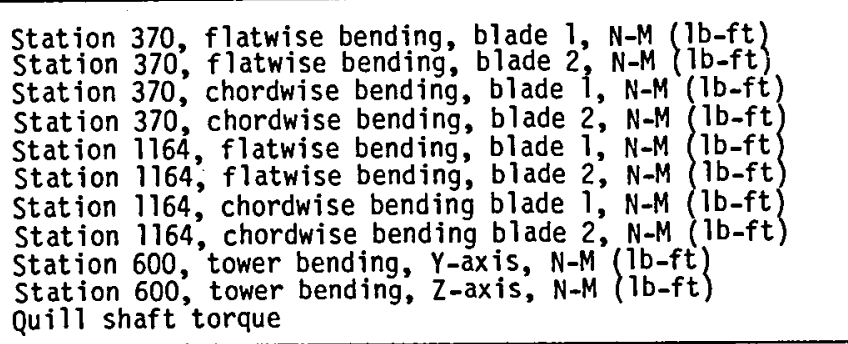 & $\begin{array}{r} \pm 4.5\left( \pm 3.3 \times 10^{-6}\right) \\
\pm 4.4( \pm 3.2 \\
\pm 16.5( \pm 12.1) \\
\pm 8.0( \pm 5.9) \\
\pm 1.3( \pm 0.95) \\
\pm 1.3( \pm 0.95) \\
\pm 1.8( \pm 1.3) \\
\pm 1.4( \pm 1.0) \\
\pm 11.6( \pm 8.5) \\
\pm 10.7( \pm 7.9) \\
\left.-0.5 \text { to } 2.2 \begin{array}{r}(-0.4 \text { to } 1.6 \\
(-0.6\end{array}\right)\end{array}$ \\
\hline Power & Generator terminal power, MW & -1.0 to +4.0 \\
\hline Meteorological & $\begin{array}{l}\text { BPA tower, wind speed at } 59.5 \mathrm{~m}(195 \mathrm{ft}), \mathrm{m} / \mathrm{s} \\
\text { BPA tower, wind direction at } 59.5 \mathrm{~m}(195 \mathrm{ft}) \text {, deg } \\
\text { PNL tower, barometric pressure at } 61.0 \mathrm{~m}(200 \mathrm{ft}) \text {, mbar } \\
\text { PNL tower, temperature at } 15.3 \mathrm{~m}(50 \mathrm{ft}){ }^{\circ} \mathrm{C} \\
\text { PNL tower, temperature at } 107^{\circ} \mathrm{m}(350 \mathrm{ft}){ }^{\circ} \mathrm{C}\end{array}$ & $\begin{array}{l}0 \text { to } 42 \\
0 \text { to } 360 \\
875 \text { to } 975 \\
-30 \text { to } 50 \\
-30 \text { to } 50\end{array}$ \\
\hline
\end{tabular}

TABLE II. - VORTEX GENERATOR TEST SERIES

\begin{tabular}{|c|c|c|c|c|c|c|}
\hline \multirow[t]{2}{*}{ Configuration } & \multirow[t]{2}{*}{$\begin{array}{l}\text { Date } \\
\text { (1983) }\end{array}$} & \multirow{2}{*}{$\begin{array}{l}\text { Average } \\
\text { wind } \\
\text { speed, } \\
\mathrm{m} / \mathrm{sec}\end{array}$} & \multirow{2}{*}{$\begin{array}{l}\text { Average } \\
\text { wind } \\
\text { direction, } \\
\text { deg }\end{array}$} & \multirow{2}{*}{$\begin{array}{c}\text { Average } \\
\text { generator } \\
\text { power, } \\
\text { MW }\end{array}$} & \multicolumn{2}{|c|}{$\begin{array}{c}\text { Data analyzed, } \\
\mathrm{hr}\end{array}$} \\
\hline & & & & & Performance & Loads \\
\hline No $V G$ & $\begin{array}{l}7 / 11 \\
7 / 12 \\
7 / 13\end{array}$ & $\begin{array}{l}14.4 \\
11.7 \\
13.9\end{array}$ & $\begin{array}{l}269 \\
270 \\
267\end{array}$ & $\begin{array}{l}2.05 \\
1.37 \\
2.02\end{array}$ & $\begin{array}{l}3.2 \\
6.2 \\
2.5\end{array}$ & $\begin{array}{l}3.0 \\
6.0 \\
2.0\end{array}$ \\
\hline 70 Percent $V G$ & $\begin{array}{l}7 / 19 \\
7 / 25 \\
7 / 27\end{array}$ & $\begin{array}{r}15.2 \\
9.0 \\
9.9\end{array}$ & $\begin{array}{l}274 \\
257 \\
266\end{array}$ & $\begin{array}{r}2.38 \\
.78 \\
1.03\end{array}$ & $\begin{array}{l}4.7 \\
4.5 \\
2.8\end{array}$ & $\begin{array}{l}4.5 \\
4.0 \\
2.5\end{array}$ \\
\hline 100 Percent VG & $\begin{array}{l}8 / 1 \\
8 / 2\end{array}$ & $\begin{array}{l}10.7 \\
13.2\end{array}$ & $\begin{array}{l}259 \\
270\end{array}$ & $\begin{array}{l}1.20 \\
2.28\end{array}$ & $\begin{array}{l}6.0 \\
3.2\end{array}$ & $\begin{array}{l}5.5 \\
3.0\end{array}$ \\
\hline
\end{tabular}


TABLE III. - COMPARISON OF WIND PARAMETERS WITH CYCLIC LOADS AND POWER

[The standard deviation of the steady wind speed was $1.55 \mathrm{~m} / \mathrm{sec}$ for segment $A$ and $0.45 \mathrm{~m} / \mathrm{sec}$ for segment $B$.]

\begin{tabular}{|c|c|c|c|c|c|c|c|c|c|}
\hline \multirow{3}{*}{$\begin{array}{l}\text { Half-hour } \\
\text { segment }\end{array}$} & \multirow{2}{*}{\multicolumn{2}{|c|}{$\begin{array}{l}\text { Wind speed at } 195 \mathrm{ft} \text {, } \\
\mathrm{m} / \mathrm{sec}\end{array}$}} & \multicolumn{2}{|c|}{ Station 370} & \multicolumn{2}{|c|}{ Station 1164} & $Y$-axis & Z-axis & \multirow{3}{*}{$\begin{array}{l}\text { Cyclic } \\
\text { power, } \\
\mathrm{kW}\end{array}$} \\
\hline & & & Blade 1 & Blade 2 & Blade 1 & Blade 2 & \multirow{2}{*}{\multicolumn{2}{|c|}{ Tower moment, $k N-M(k l b-f t)$}} & \\
\hline & Steady & Cyclic & \multicolumn{4}{|c|}{ Blade flatwise moment, $k N-M(k l b-f t)$} & & & \\
\hline \multicolumn{10}{|c|}{ 50th percentile probability level } \\
\hline $\begin{array}{l}\text { A } \\
B\end{array}$ & $\begin{array}{l}14.71 \\
14.83\end{array}$ & $\begin{array}{r}0.73 \\
.41\end{array}$ & $\begin{array}{l}612\left(\begin{array}{l}450 \\
324\end{array}\right) \\
441\end{array}$ & $\begin{array}{l}674 \\
514\left(\begin{array}{l}496 \\
378\end{array}\right)\end{array}$ & $\begin{array}{l}170 \\
136\left(\begin{array}{l}125 \\
100\end{array}\right)\end{array}$ & $166\left(\begin{array}{l}122 \\
091\end{array}\right)$ & $\begin{array}{l}2490 \\
1910\end{array}\left(\begin{array}{l}1830 \\
1400\end{array}\right)$ & $\left.\begin{array}{ll}1470 & (1080) \\
1190 & (870)\end{array}\right)$ & $\begin{array}{l}104 \\
082\end{array}$ \\
\hline$A / B$ & .99 & 1.78 & 1.32 & 1.31 & 1.25 & 1.34 & 1.31 & 1.24 & 1.27 \\
\hline \multicolumn{10}{|c|}{ 99th percentile probability level } \\
\hline $\begin{array}{l}A \\
B\end{array}$ & $\begin{array}{l}17.51 \\
16.12\end{array}$ & $\begin{array}{l}1.94 \\
1.17\end{array}$ & $\begin{array}{r}1100\left(\begin{array}{l}809 \\
797\end{array}(586)\right. \\
0\end{array}$ & $\begin{array}{r}1244 \\
873\left(\begin{array}{l}915 \\
642\end{array}\right)\end{array}$ & $\begin{array}{l}262 \\
209\end{array}\left(\begin{array}{l}193 \\
514\end{array}\right)$ & $\left.\begin{array}{r}1283\left(\begin{array}{l}208 \\
196\end{array}\right) \\
144\end{array}\right)$ & $\begin{array}{l}5070 \\
4150(3730) \\
3050)\end{array}$ & $\begin{array}{l}3160 \\
2310\end{array}\left(\begin{array}{l}2320 \\
1700\end{array}\right)$ & $\begin{array}{l}236 \\
179\end{array}$ \\
\hline$A / B$ & 1.09 & 1.66 & 1.38 & 1.42 & 1.25 & 1.44 & 1.23 & 1.37 & 1.32 \\
\hline
\end{tabular}

TABLE IV. - CALCULATION OF PROJECTED ANNUAL ENERGY CAPTURE

(100 PERCENT AVAILABILITY)

\begin{tabular}{|c|c|c|c|c|c|c|c|}
\hline \multirow{2}{*}{$\begin{array}{l}\text { Wind } \\
\text { speed } \\
\text { range, } \\
\mathrm{m} / \mathrm{sec}\end{array}$} & \multirow{2}{*}{$\begin{array}{c}\text { Time } \\
\text { within } \\
\text { wind } \\
\text { speed } \\
\text { range, a } \\
\mathrm{hr} / \mathrm{yr}\end{array}$} & \multicolumn{3}{|c|}{ Average measured power, MW } & \multicolumn{3}{|c|}{ Energy capture, MW-hr } \\
\hline & & $\begin{array}{l}\text { No } \\
\text { VG's }\end{array}$ & $\begin{array}{c}70 \text { Percent } \\
\text { VG's }\end{array}$ & $\begin{array}{c}100 \text { Percent } \\
\text { VG's }\end{array}$ & $\begin{array}{l}\text { No } \\
\text { VG's }\end{array}$ & $\begin{array}{c}70 \text { Percent } \\
\text { VG's }\end{array}$ & $\begin{array}{c}100 \text { Percent } \\
\text { VG's }\end{array}$ \\
\hline 0 to 6 & 1950 & 0 & 0 & 0 & 0 & 0 & 0 \\
\hline 6 to 7 & 829 & 0 & .079 & .120 & 0 & 65 & 99 \\
\hline 7 to 8 & 914 & .250 & .373 & .436 & 229 & 341 & 399 \\
\hline 8 to 9 & 939 & .609 & .679 & .763 & 572 & 638 & 716 \\
\hline 9 to 10 & 905 & .941 & .997 & 1.103 & 852 & 902 & 998 \\
\hline 10 to 11 & 820 & 1.248 & 1.327 & 1.455 & 1023 & 1088 & 1193 \\
\hline 11 to 12 & 696 & 1.530 & 1.669 & 1.820 & 1065 & 1162 & 1267 \\
\hline $\begin{array}{l}12 \text { to } 13 \\
13 \text { to } 14\end{array}$ & $\begin{array}{l}557 \\
416\end{array}$ & $\begin{array}{l}1.786 \\
2.016\end{array}$ & $\begin{array}{l}2.023 \\
2.389\end{array}$ & $\begin{array}{l}2.196 \\
2.450\end{array}$ & $\begin{array}{l}995 \\
839\end{array}$ & $\begin{array}{r}1127 \\
994\end{array}$ & $\begin{array}{l}1223 \\
1019\end{array}$ \\
\hline 14 to 15 & 292 & 2.220 & 2.450 & 2.450 & 648 & 715 & 715 \\
\hline 15 to 16 & 192 & 2.400 & 2.450 & 2.450 & 461 & 470 & 470 \\
\hline 16 to 19 & 219 & 2.450 & 2.450 & 2.450 & 537 & 537 & 537 \\
\hline $19+$ & 31 & & 0 & 0 & 0 & 0 & 0 \\
\hline Total & 8760 & ---- & $-\ldots$ &.--- & 7221 & 8039 & 8636 \\
\hline \multicolumn{5}{|c|}{ Ratio to no VG configuration } & 1.00 & 1.11 & 1.20 \\
\hline
\end{tabular}

Weibull distribution at hub elevation, $c=10.0 \mathrm{~m} / \mathrm{sec}, \mathrm{k}=2.70$. 


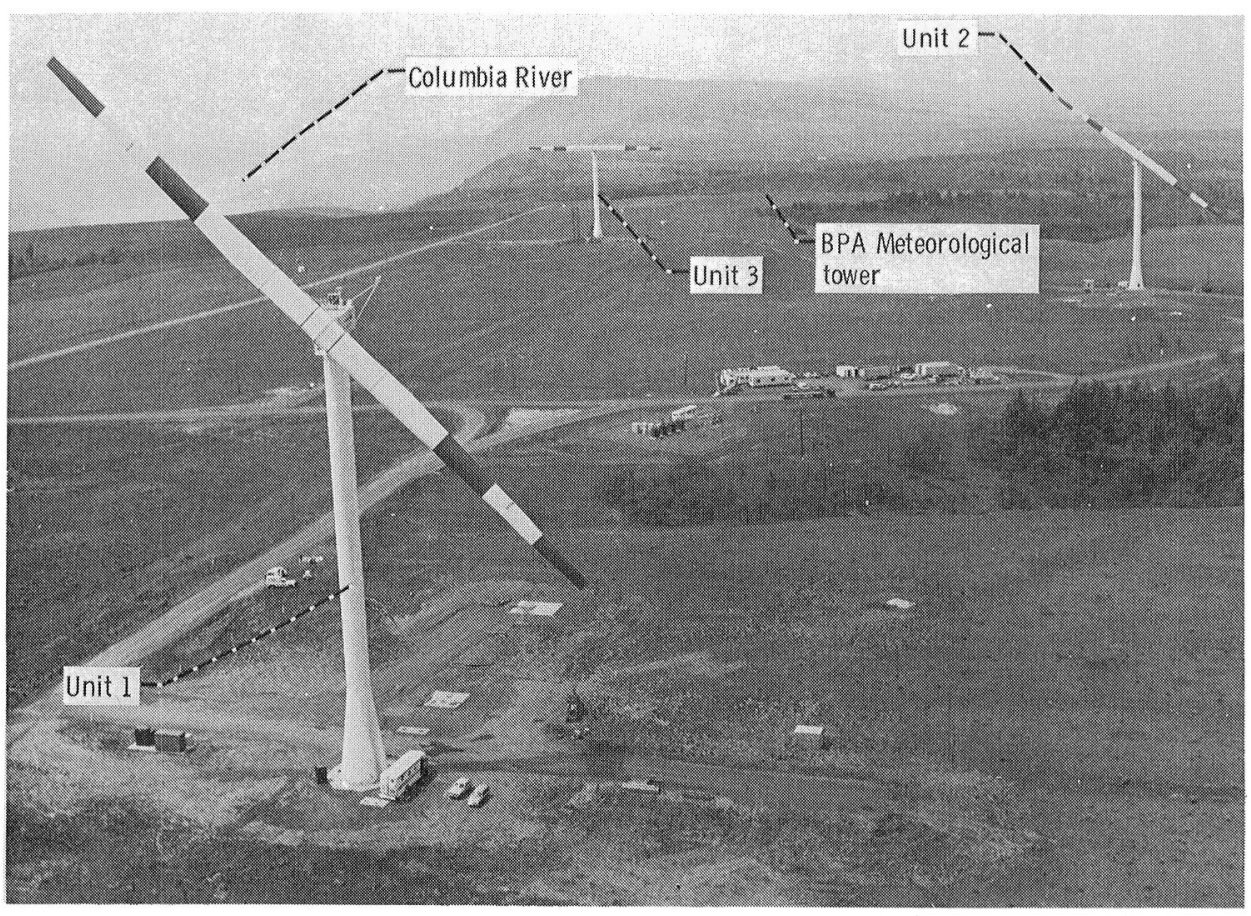

Figure 1. - Mod-2 wind turbine cluster test site at Goldendale, Washington.

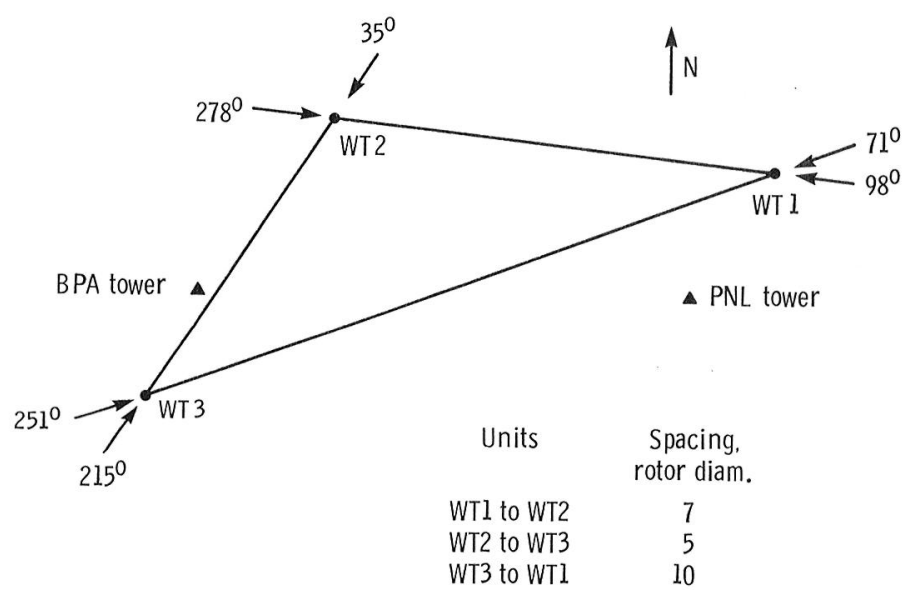

Figure 2. - Mod-2 cluster layout. 


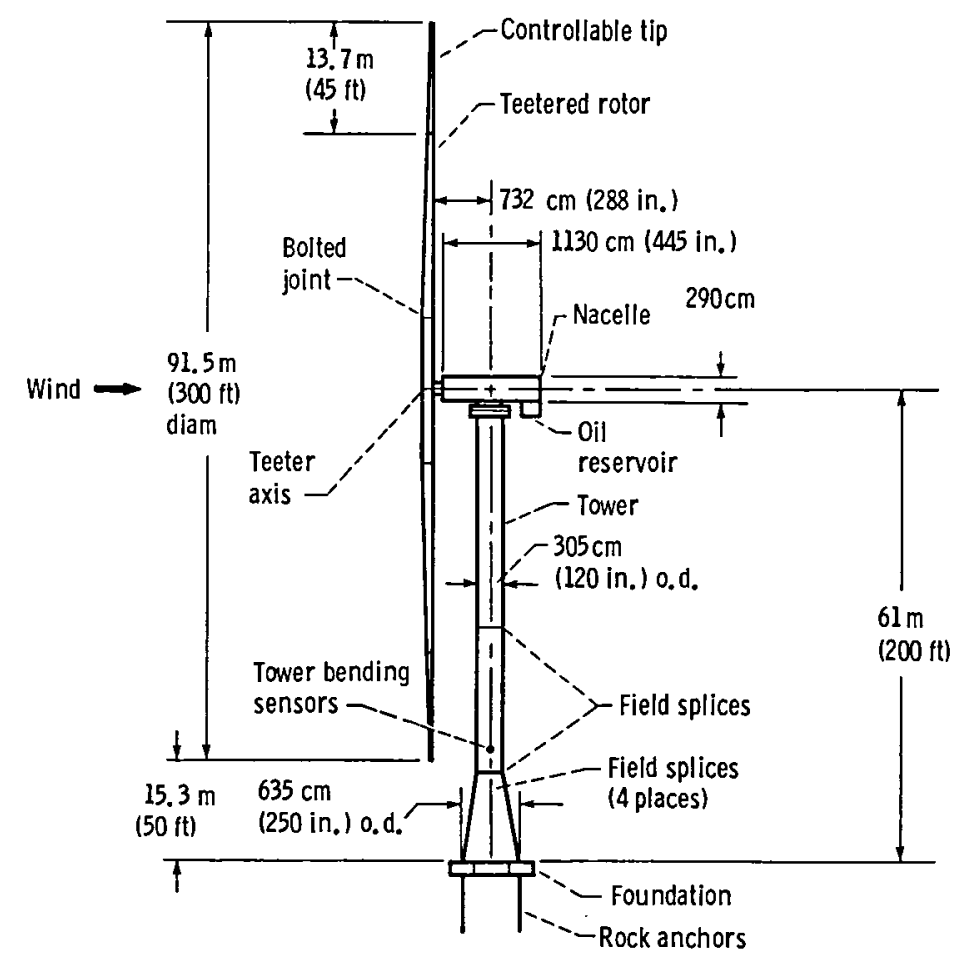

Rated power, kw . . . . . . . . . . . . . . 2500

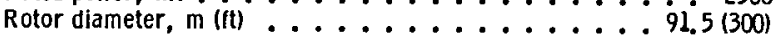

Rotor type .............. Teetered - tio control Rotor orientation. ............. Upwind $-2.5^{\circ}$ tilt

Rotor airfoil . . . . . . . . . . . . . . NACA 230XX

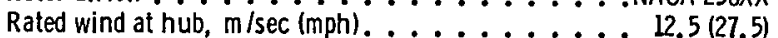
Cut-off wind speed at hub, $\mathrm{m} / \mathrm{sec}(\mathrm{m} m \mathrm{~h}) \ldots \ldots . . .20$ (45) Rotor tip speed, $\mathrm{m} / \mathrm{sec}(\mathrm{ft} / \mathrm{sec}) \ldots \ldots . . . . . . .833 .9(275)$ Rotor speed, rpm. .................... 17,5 Generator speed, rpm. . . . . . . . . . . . 1800 Generator type ................ Synchronous Gear box. . . . . . . . . . . . Compact planetary gear Hub height, $m$ (ft) . . . . . . . . . . . . . . 61 (200) Tower ................... Soft-shell tyne Pitch control ................ . . . . . . . . . . . . . . . Yaw control ................. . . . Hydraulic Electronic control .............. Microprocessor System power coefficient (max.) . . . . . . . . . . 0.382

Figure 3. - Features and dimensions of Mod-2 wind turbine. 


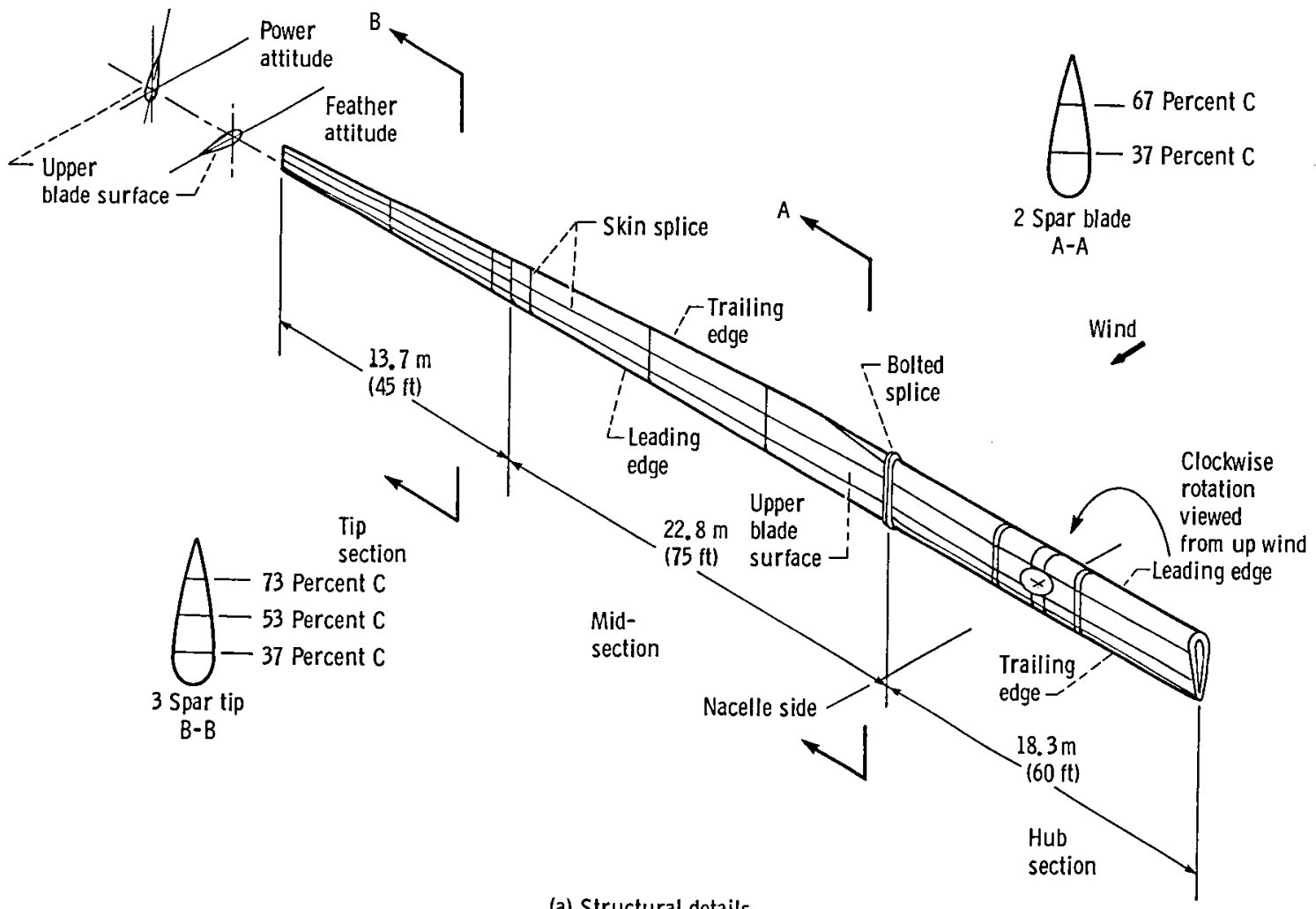

(a) Structural details.

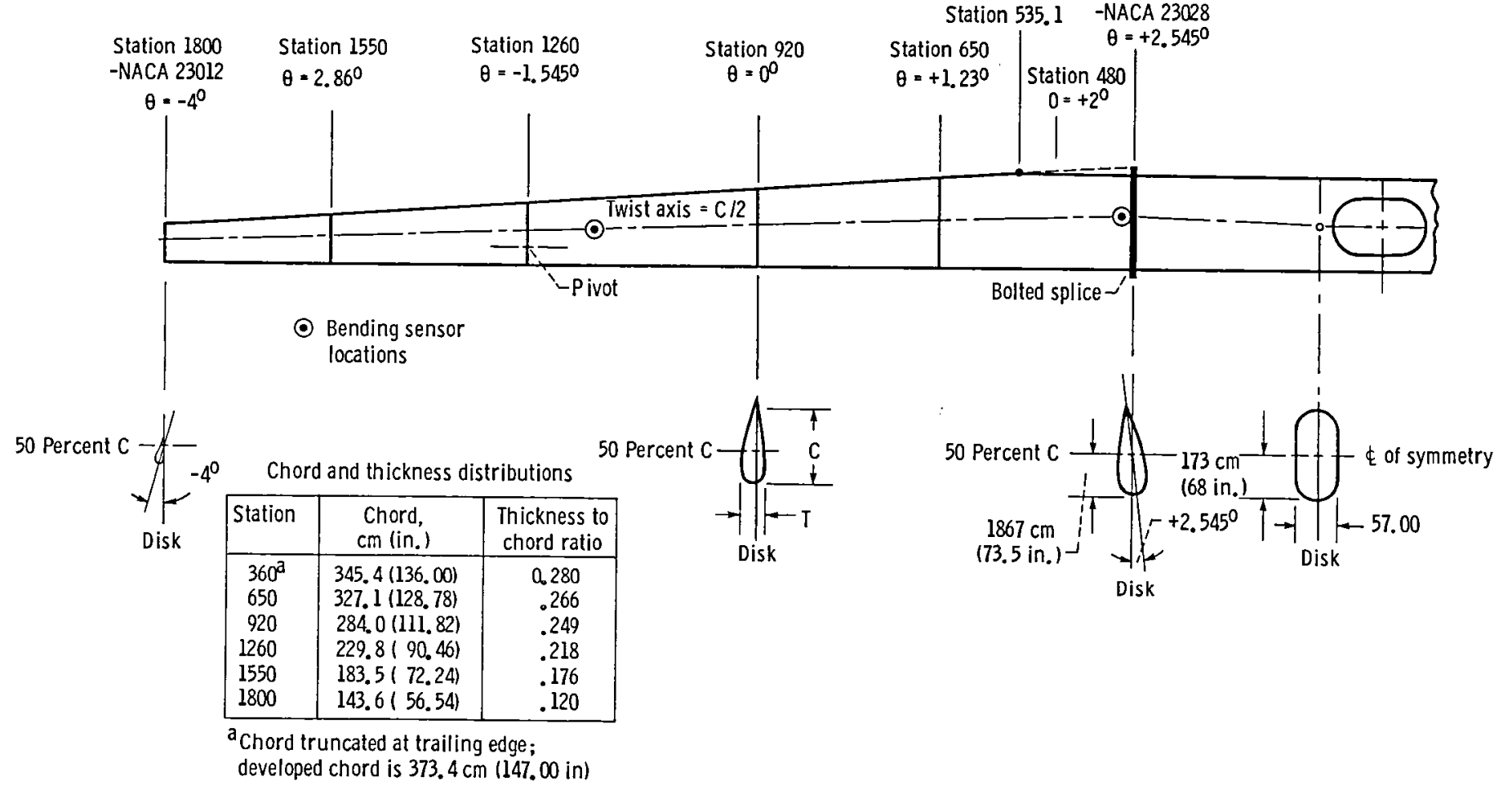

(b) Airfoil details.

Figure 4. - Mod-2 rotor. 


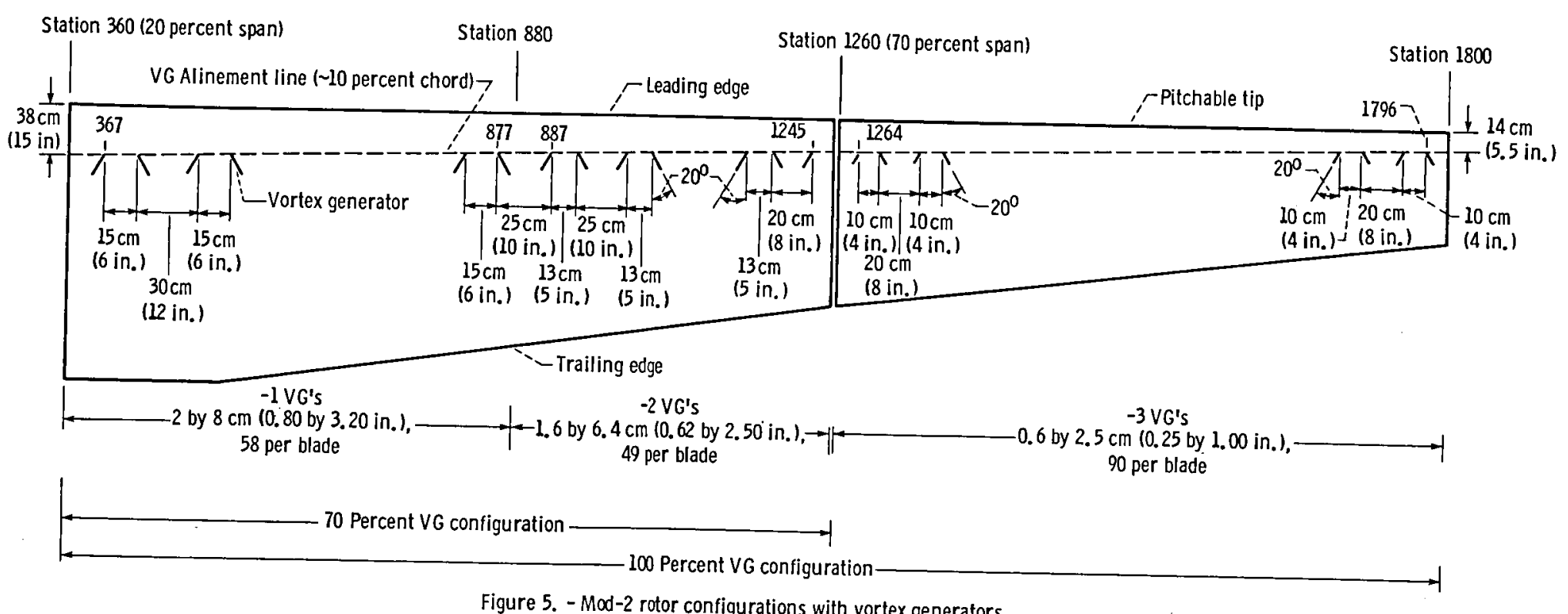

Figure 5. - Mod-2 rotor configurations with vortex generators. 


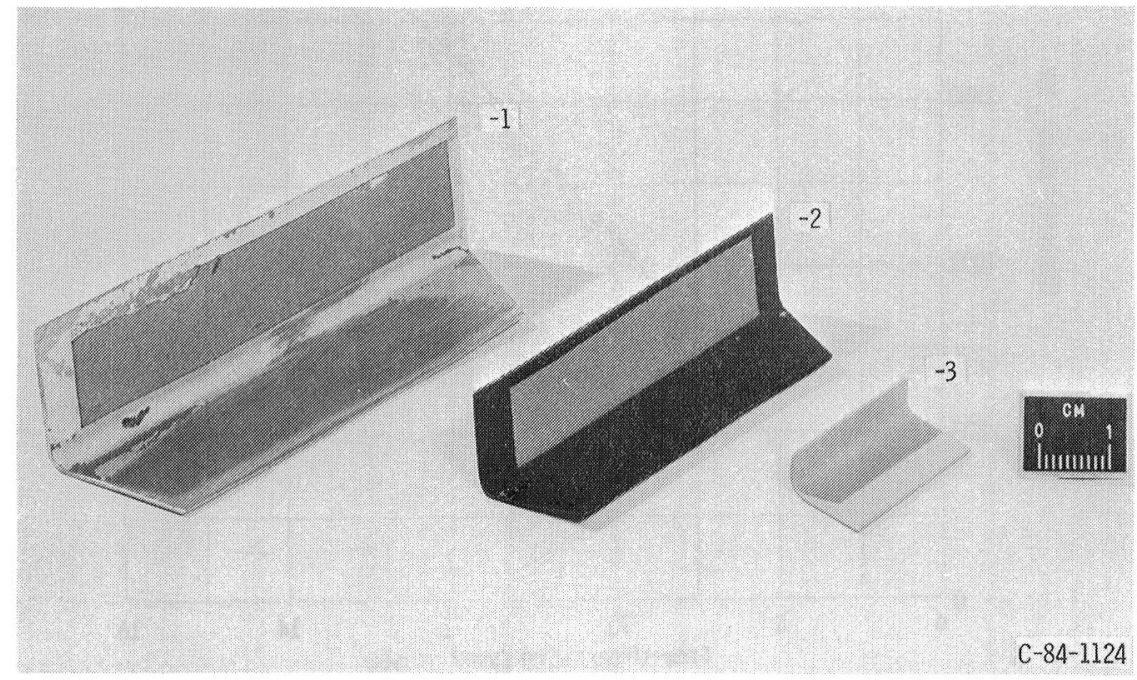

(a) Three sizes of vortex generators.

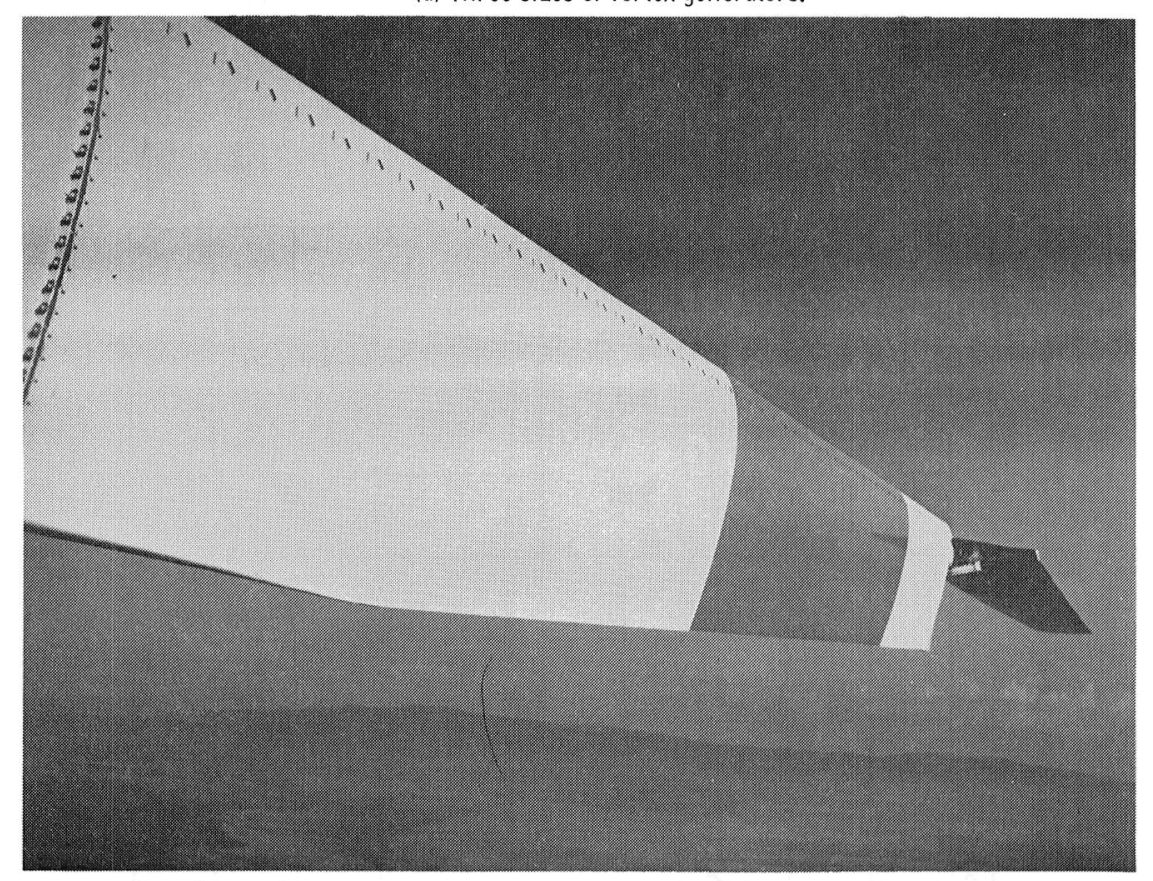

(b) Mounted on Mod-2 rotor.

Figure 6. - Vortex generators. 


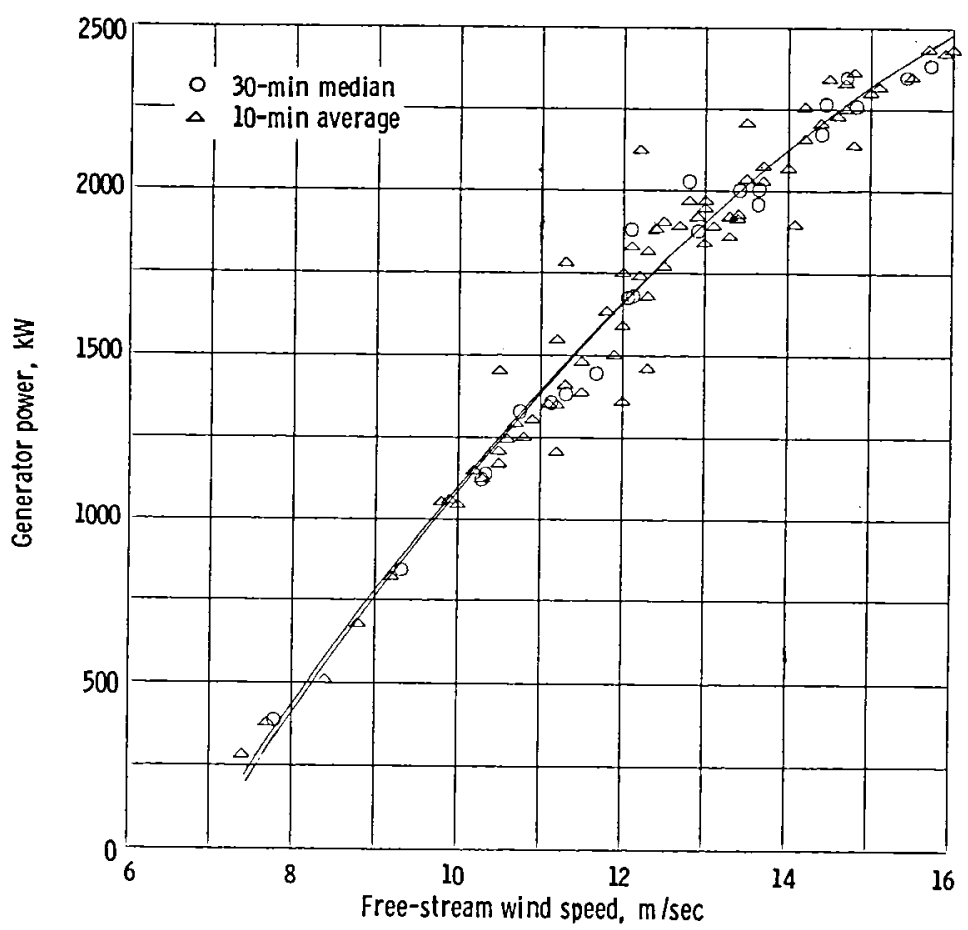

Figure 7. - Test power curves obtained using two methods of analysis (no VG configuration).

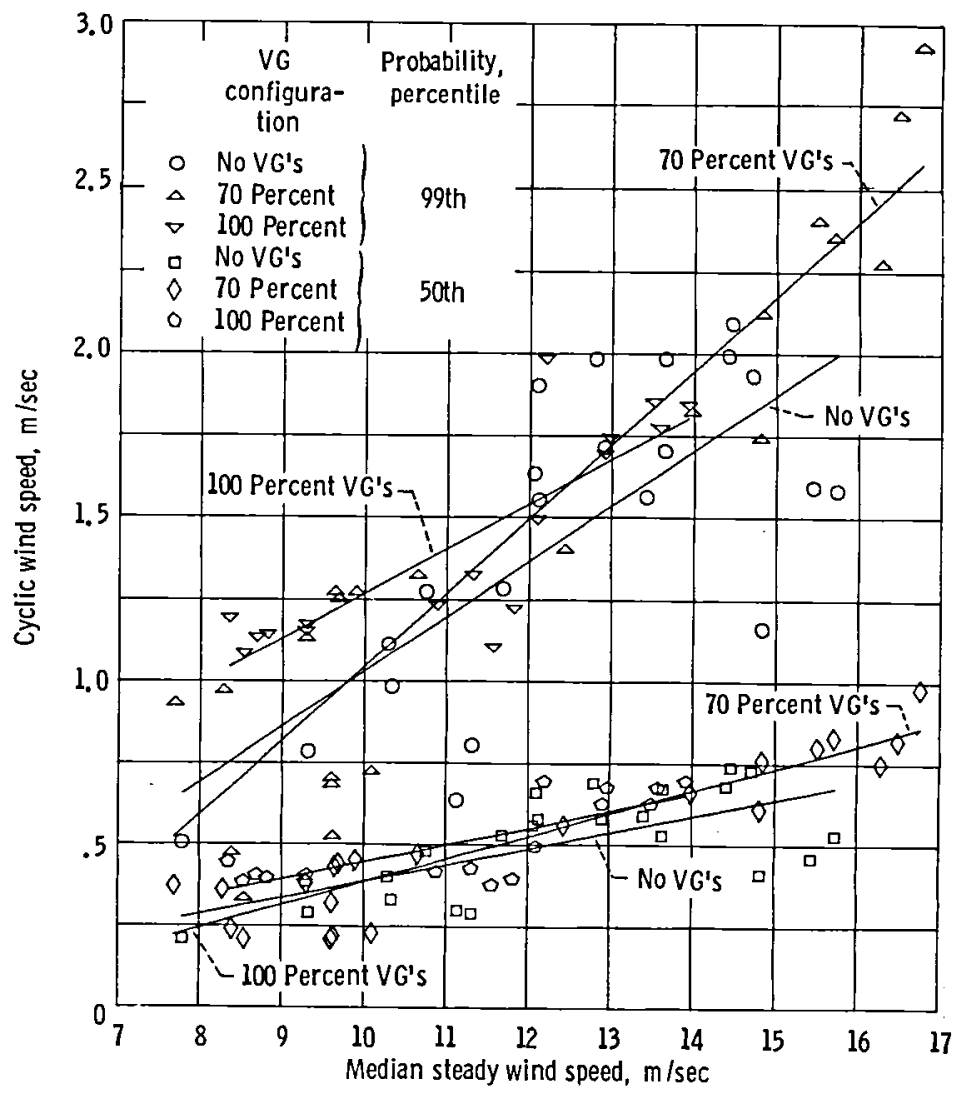

Figure 8. - Cyclic and steady wind soeeds during vortex generator tests. BPA meteorological tower; hub elevation. 


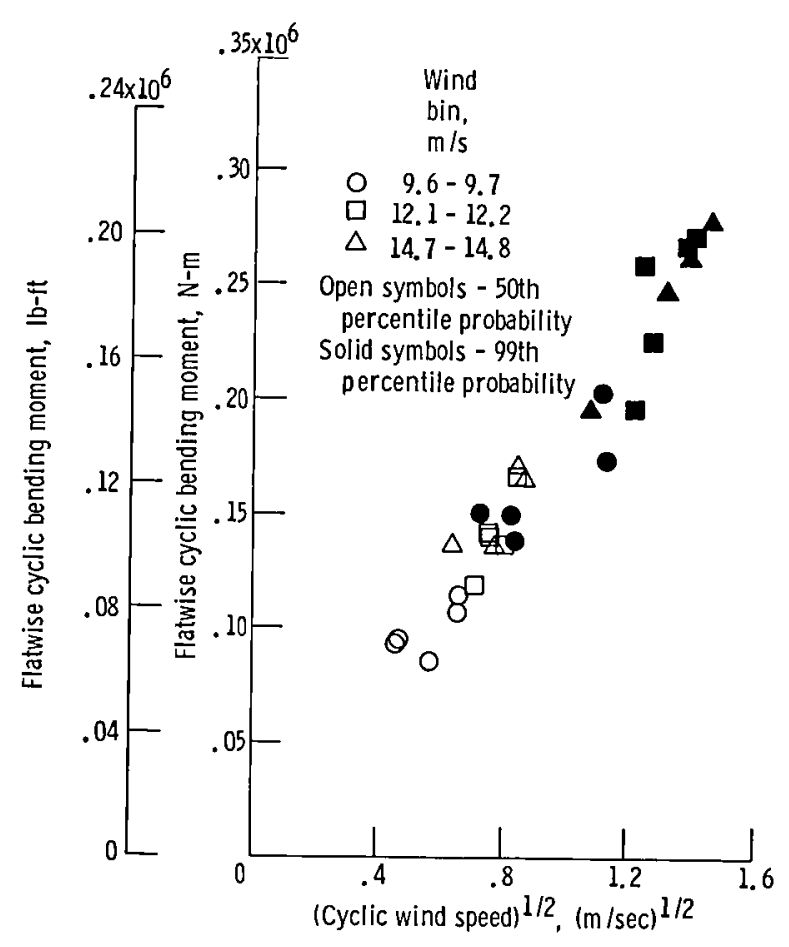

Figure 9. - Relationship between cyclic blade moment and cyclic wind speed. Station 1164; blade 1.

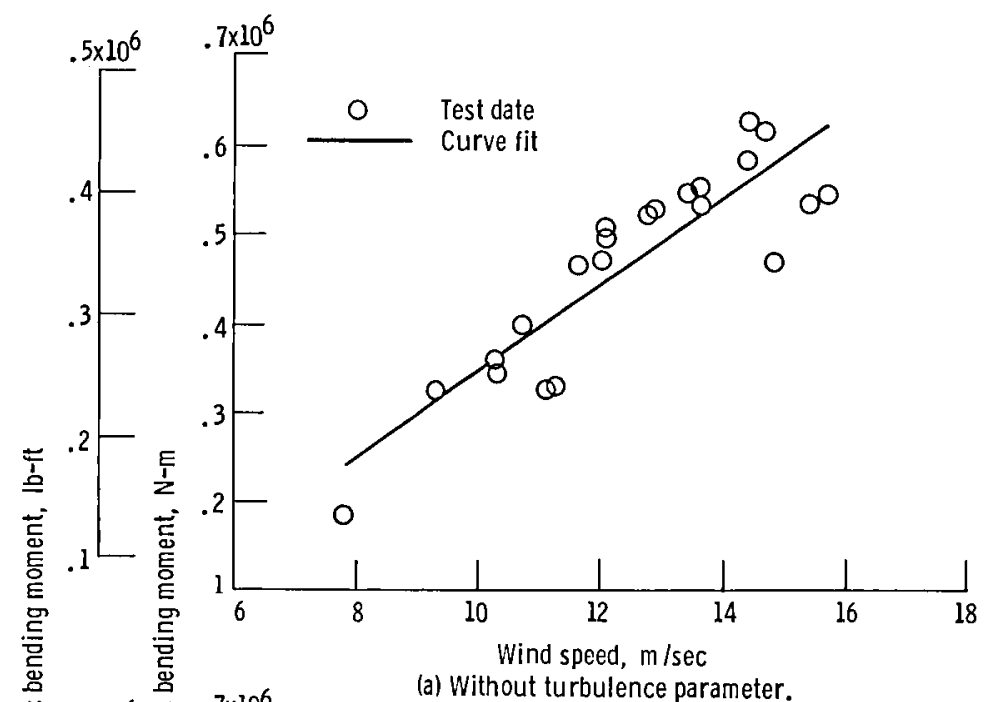

(a) Without turbulence parameter.

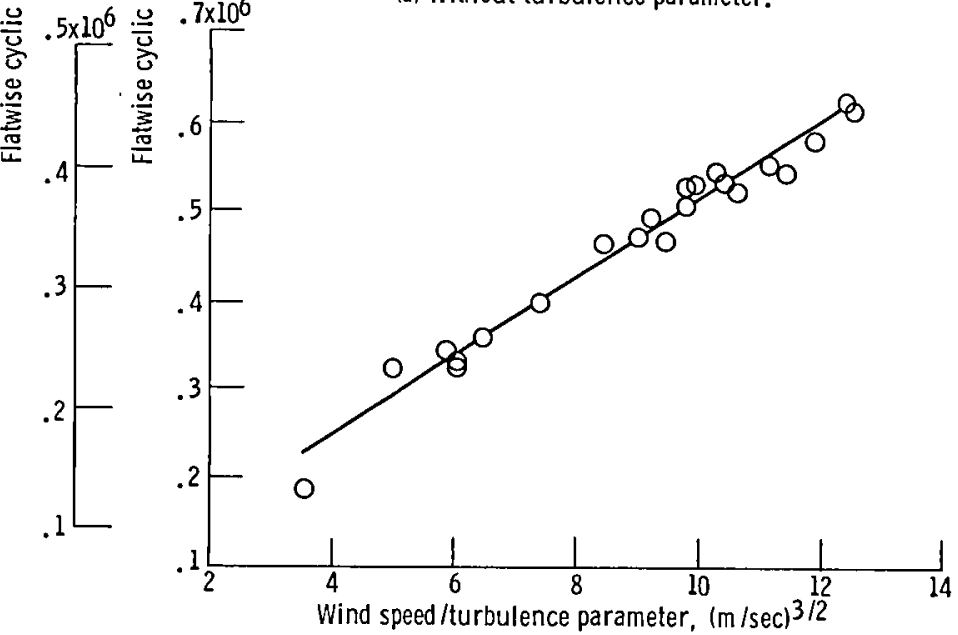

(b) With turbulence parameter.

Figure 10. - Effect of turbulence narameter on cyclic rotor load data scatter. Station 370; blade 1 ; no VG configuration. 


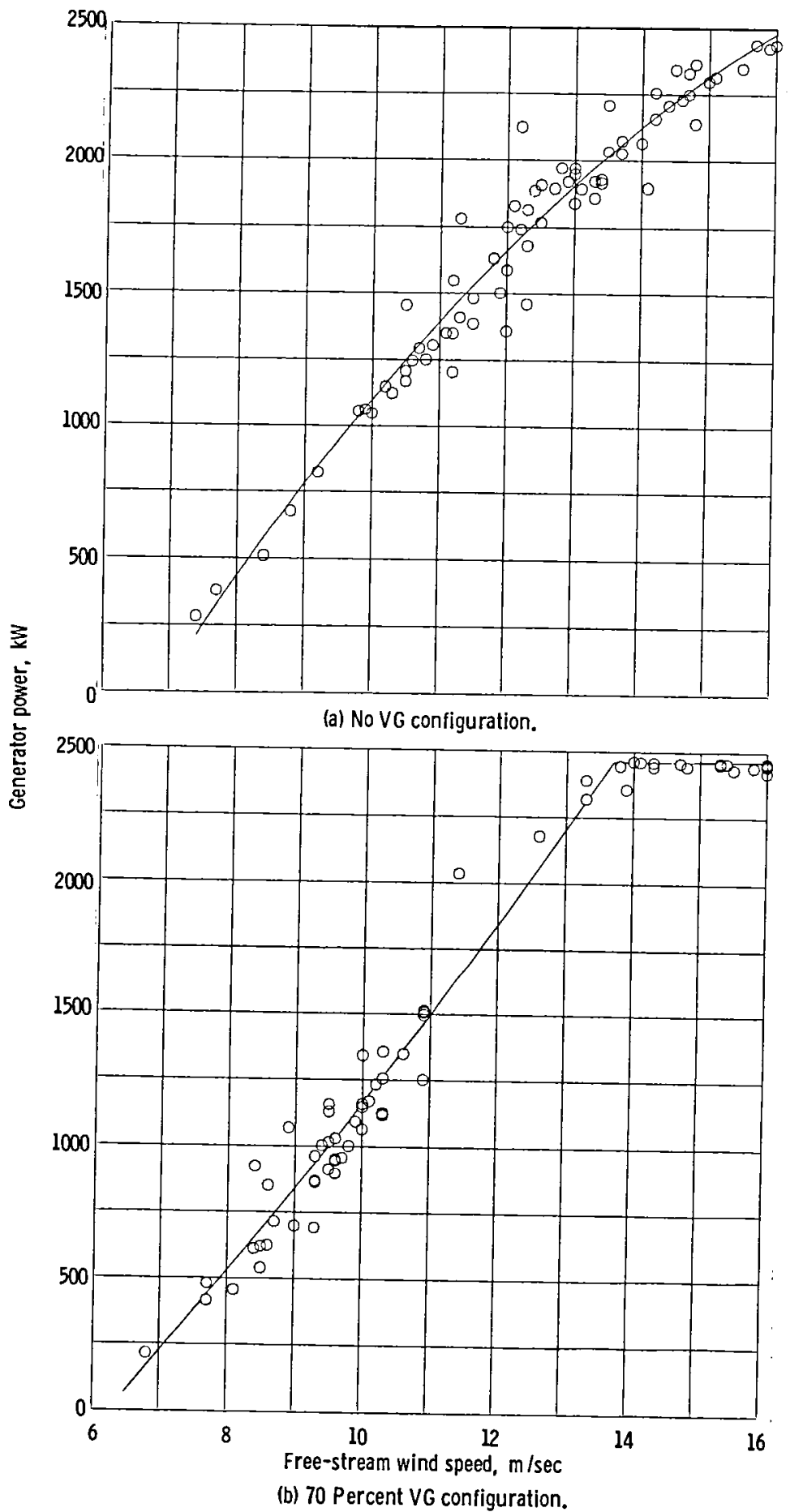

Figure 11. - Effect of vortex generators on Mod-2 power. 10-Min. average data ; site standard conditions: air density, $1.127 \mathrm{~kg} / \mathrm{m}^{3}$. 


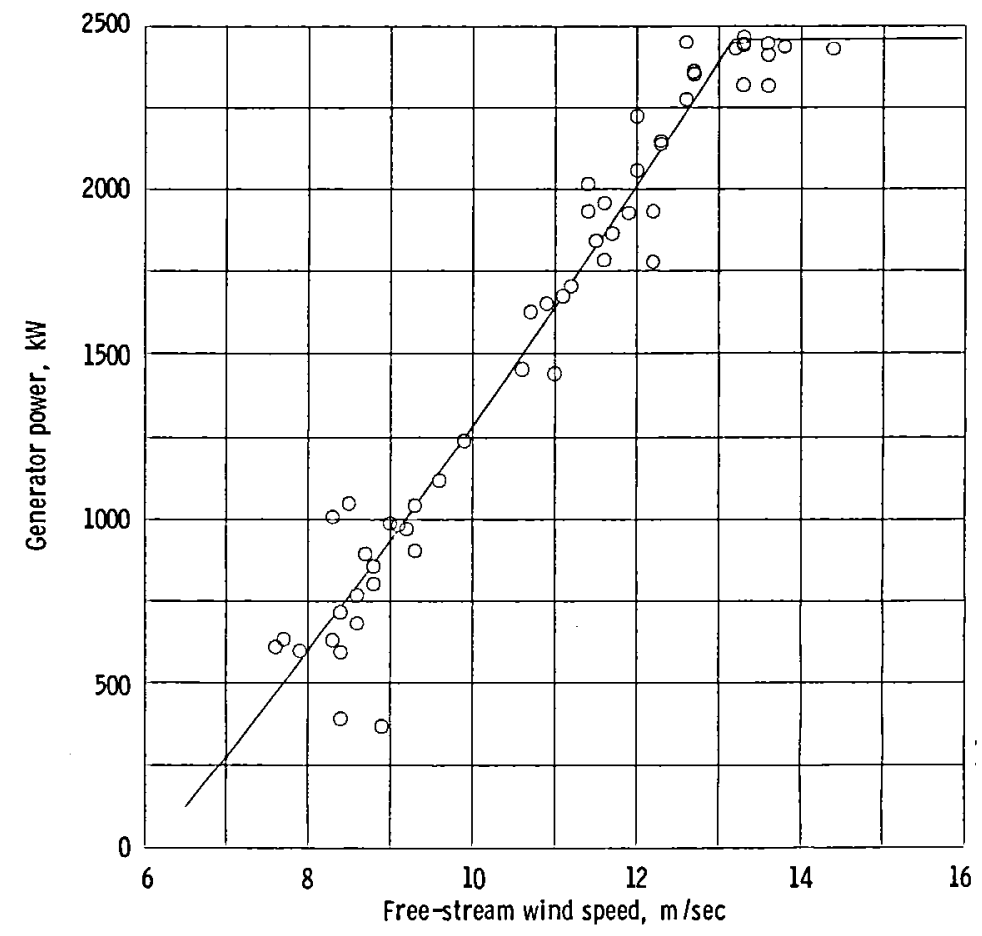

(c) 100 Percent VG configuration.

Figure 11. - Conciuded.

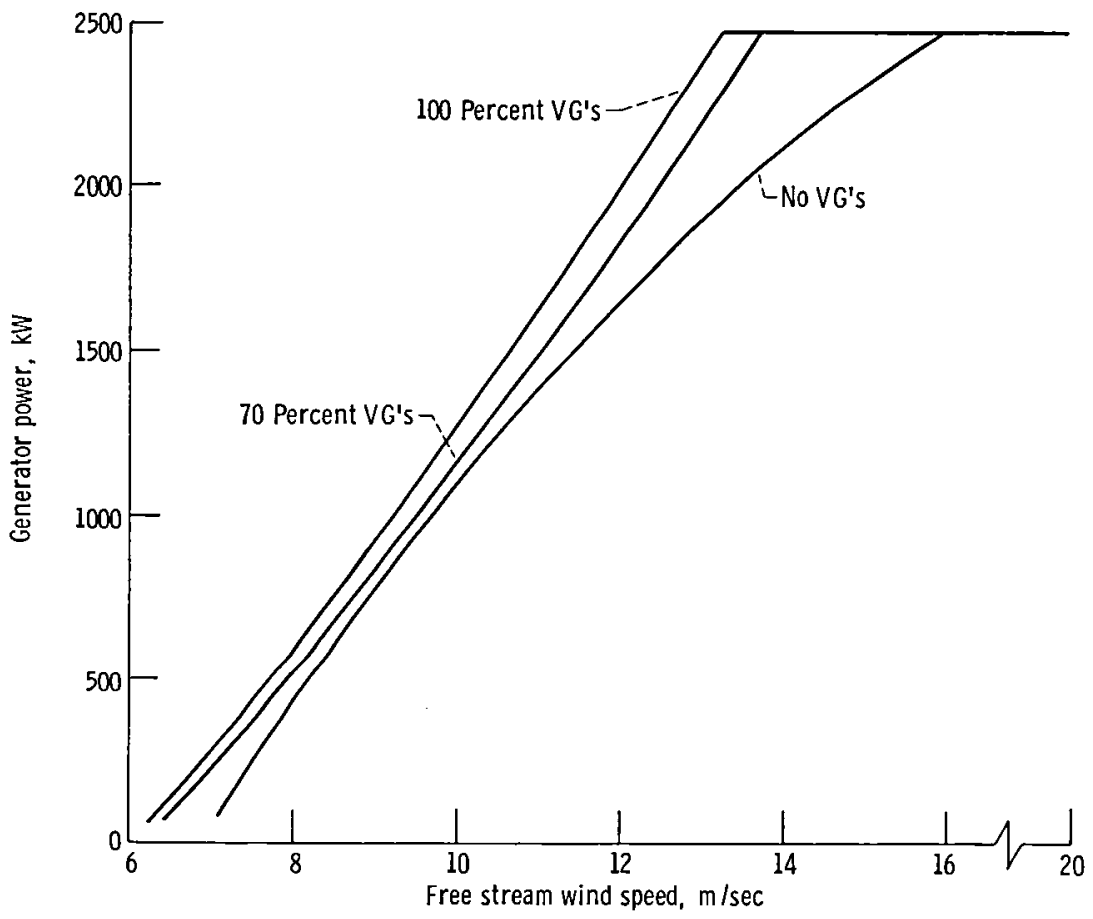

Figure 12. - Comparison of performance data curve fits from vortex generator tests. Site standard conditions: air density, $=1.127 \mathrm{~kg} / \mathrm{m}^{3}$. 


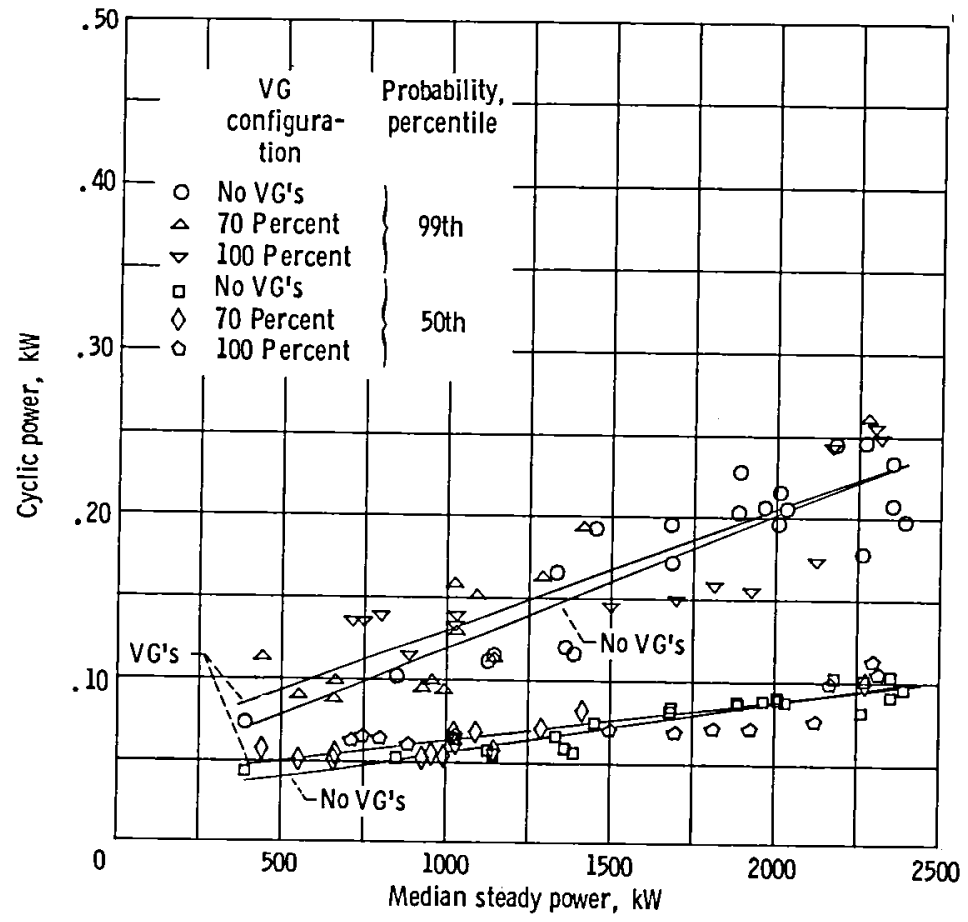

Figure 13. - Effect of vortex generators on Mod-2 generator power quality. 


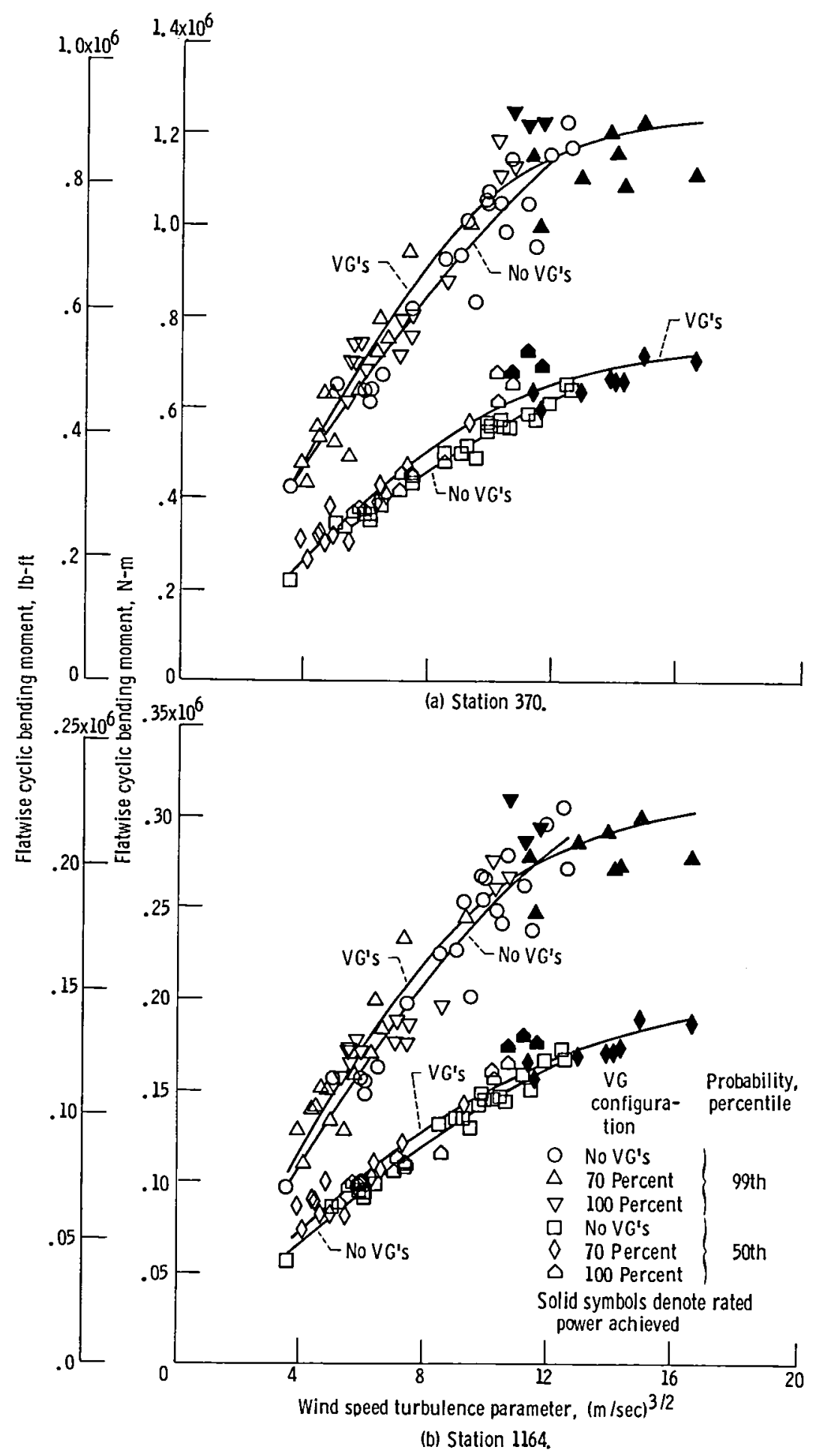

Figure 14. - Effect of vortex generators on Mod-2 blade flatwise cyclic loads. 


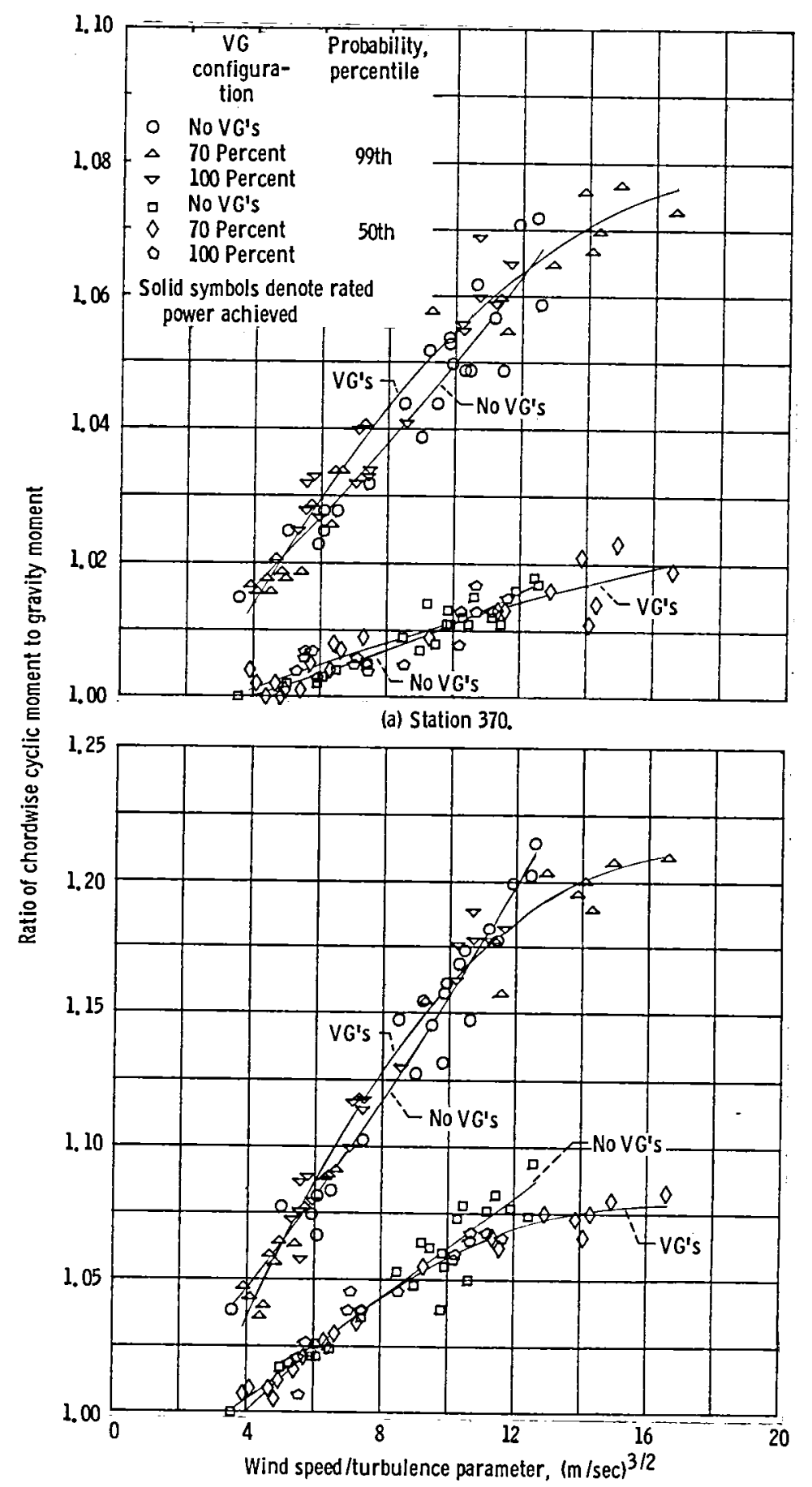

(b) Station 1164

Figure 15. - Effect of vortex generators on Mod-2 blade chordwise cyclic loads. 


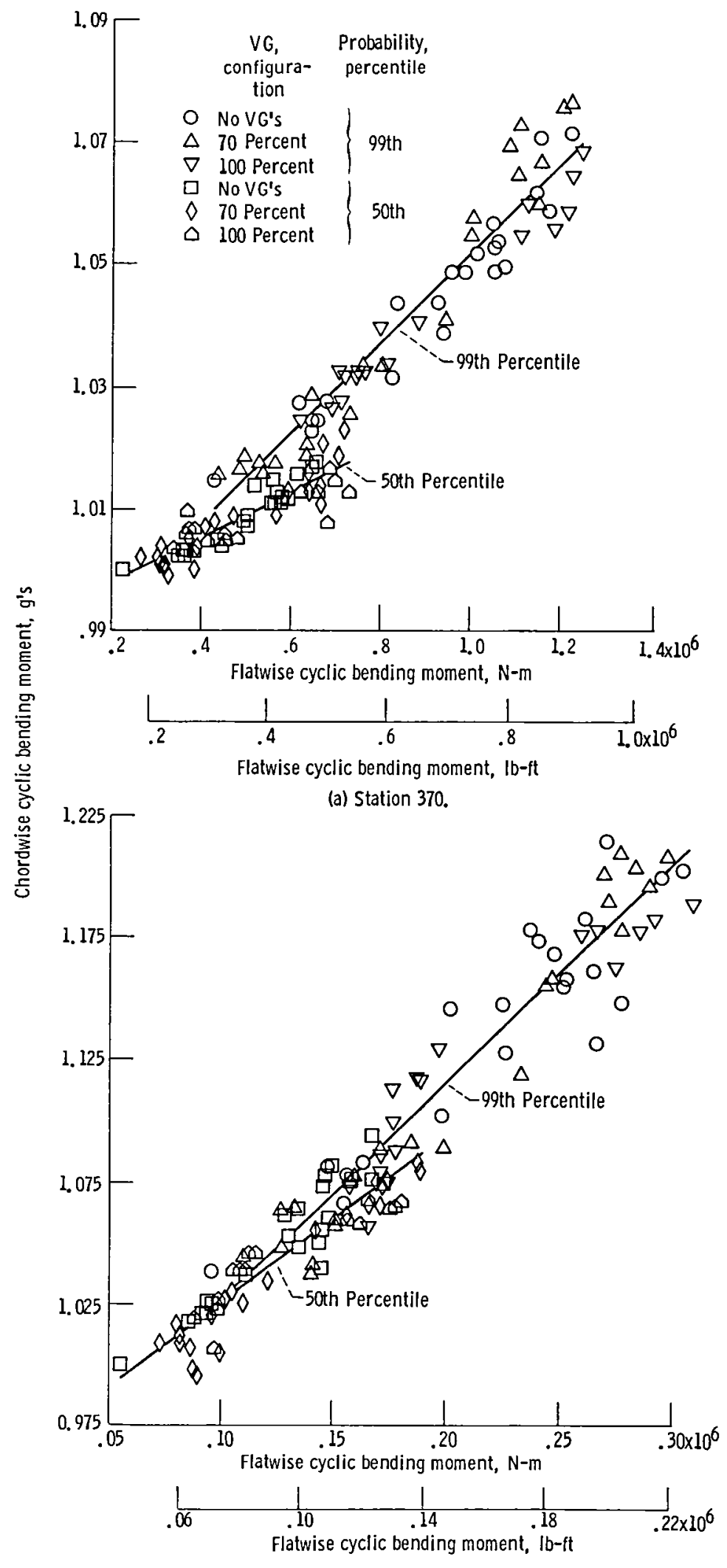

(b) Station 1164.

Figure 16. - Relationship of flatwise and chordwise cyclic loads. 


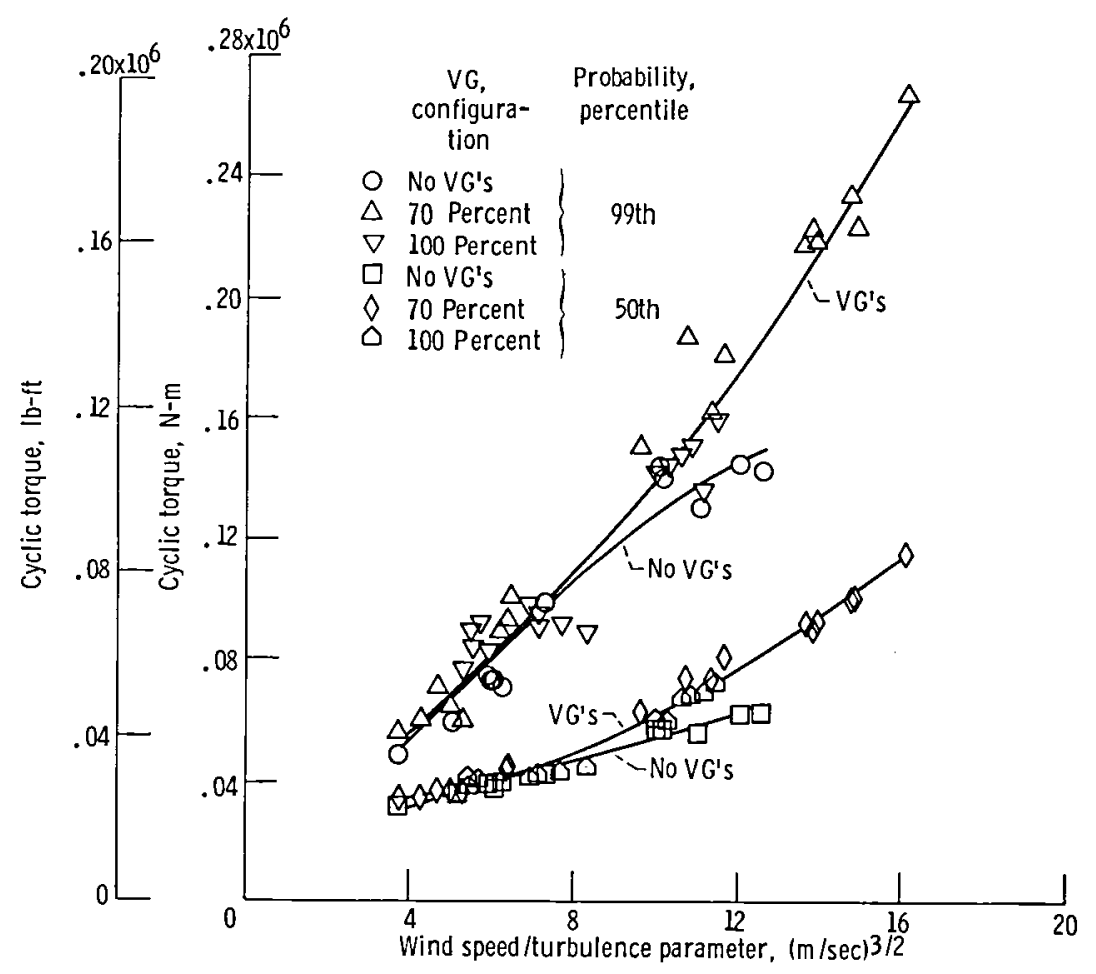

Figure 17. - Effect of vortex generators on Mod-2 quill shaft cyclic torque.

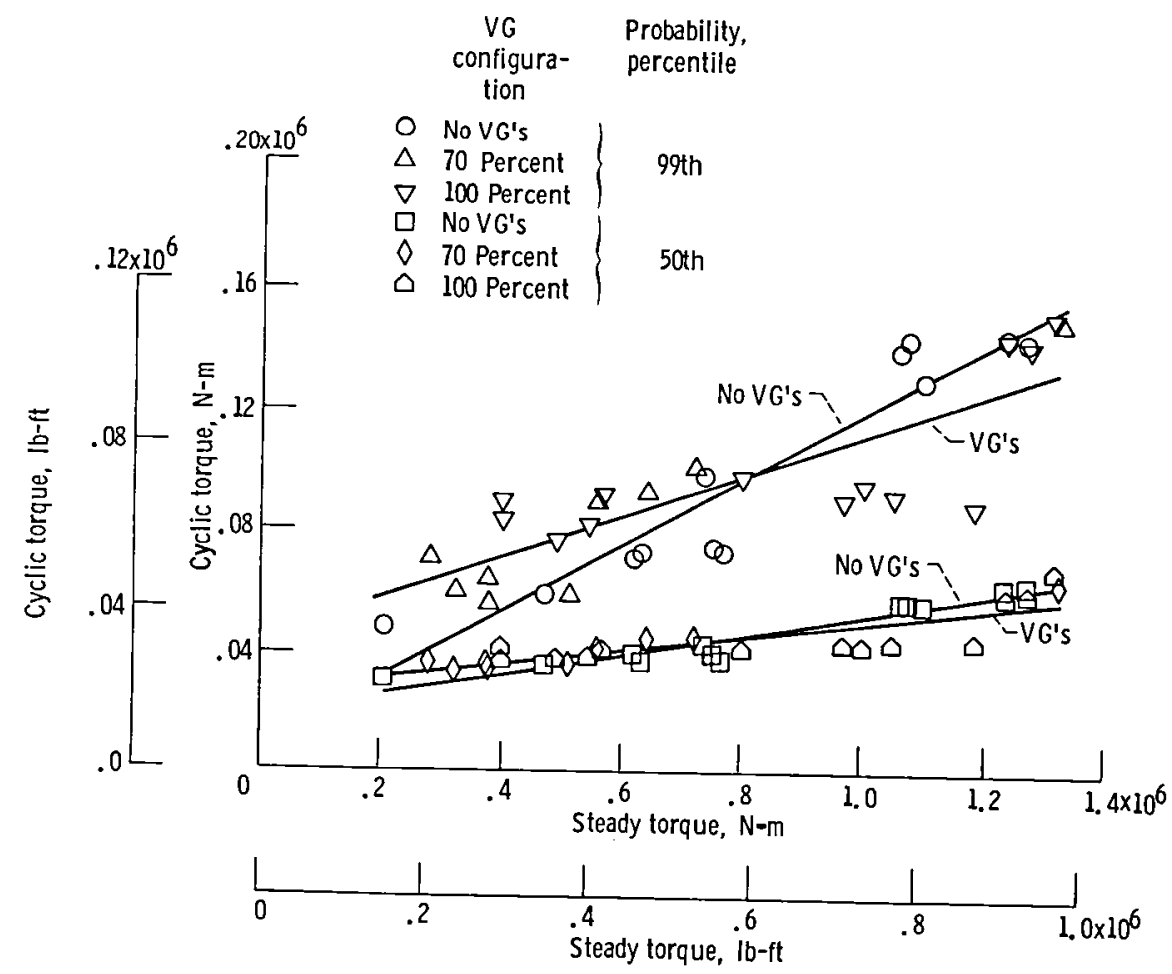

Figure 18. - Relationship of cyclic and steady quill shaft torque for below rated operation of the Mod-2. 


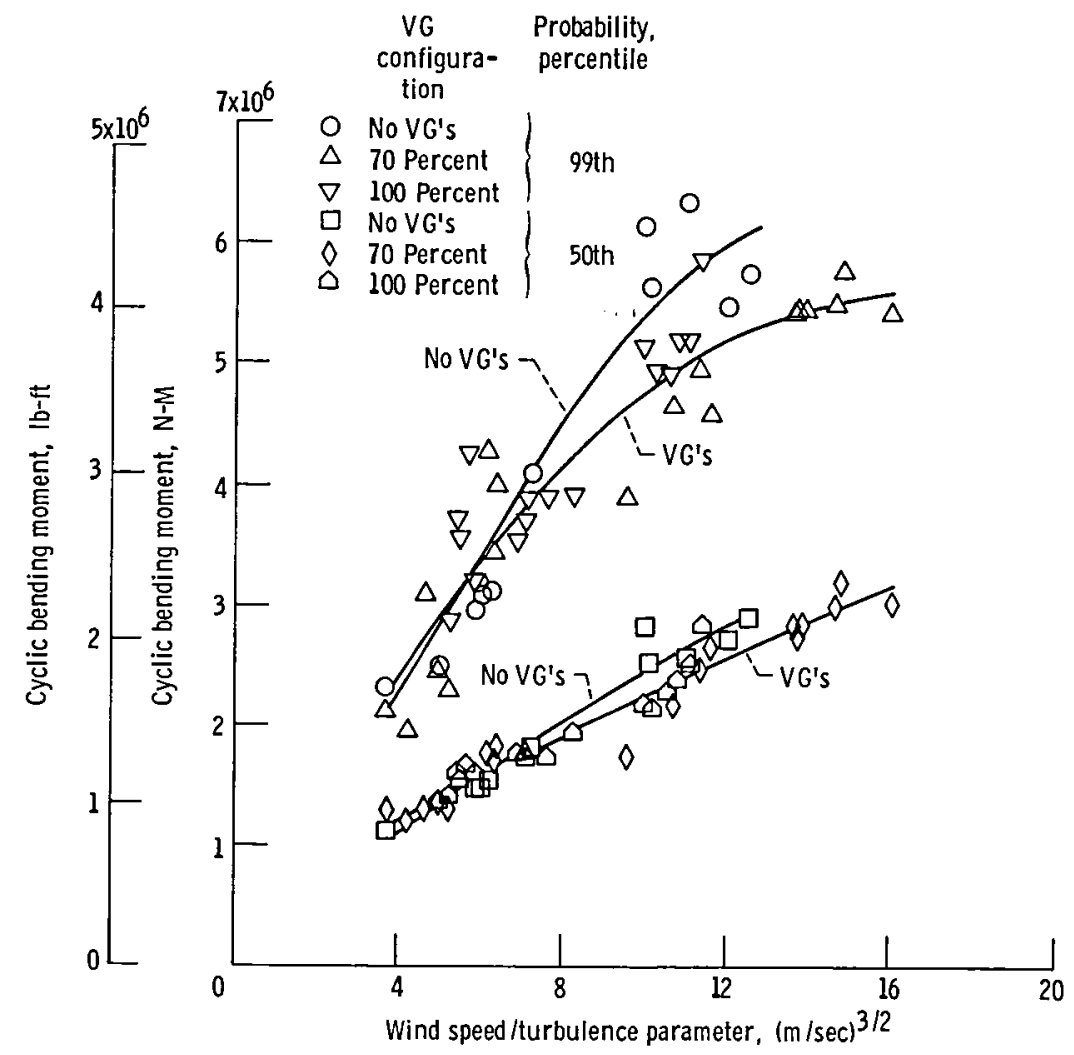

Figure 19. - Effect of vortex generators on Mod-2 tower cyclic loads. Station 600 resultant. 


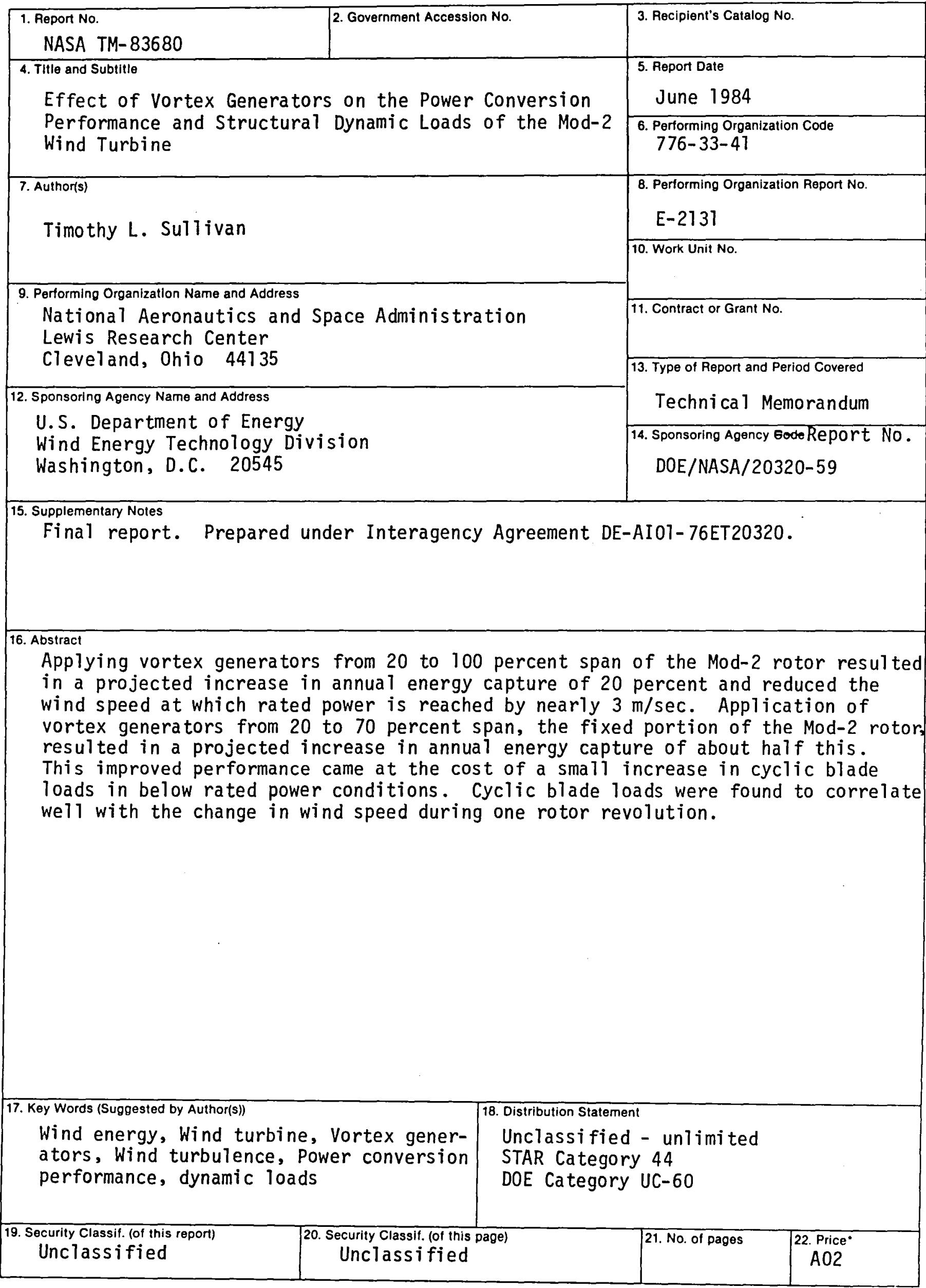

"For sale by the National Technical Information Service, Springfield, Virginia 22161 
United States Department of Energy

Office of Scientific and Technical Information

Post Office Box 62

Oak Ridge, Tennessee 37831

OFFICIAL BUSINESS

PENALTY FOR PRIVATE USE, $\$ 300$

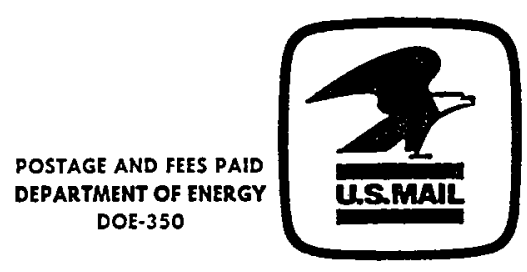

$F S^{-} \quad i$

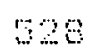

HATEOHA AEROHAUTICS AMU SFACE AH

ATU LIDAAFY

LAUGLE FESEAFCH CEUTEF

HAMTOH: पी

2366 